\title{
Chiropractic case reports: a review and bibliometric analysis
}

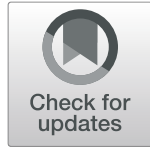

Robert J. Trager * (D) and Jeffery A. Dusek

\begin{abstract}
Objective: To determine publication trends, gaps, and predictors of citation of chiropractic case reports (CRs).

Methods: A bibliometric review was conducted by searching PubMed, Index to Chiropractic Literature (ICL), and Google Scholar to identify PubMed-indexed CRs, which were screened according to selection criteria. Case reports were categorized by International Classification of Disease (ICD-10) code, patient age, topic describing case management or adverse effects of care, focus being spinal or non-spinal, journal type, integrative authorship, title metrics, and citation metrics. Binary logistic regression was used to identify independent predictors of citations per year and total citations greater than the median values.

Results: The search identified 1176 chiropractic CRs meeting selection criteria. There was an increasing trend of CRs having a case management topic, non-spinal focus, non-chiropractic journal, neuromusculoskeletal-focus, diagnosis of vascular pathology, and a decreasing trend of adverse effect vascular pathology CRs. Independent predictors of greater total citations (or citation rate) included ICD-10 categories of perinatal conditions, infections, "case" in title, case management topic, and physical therapy, integrative, and dental journal type. Predictors of fewer citations included diseases of the blood, neoplasms, other findings not elsewhere classified, a title $>11$ words, and multidisciplinary authorship. ICD-10 categories describing non-musculoskeletal diseases and special populations such as pediatrics, pregnancy, and perinatal conditions had few CRs.

Conclusion: Chiropractic CRs are diversifying from spine-related topics. Chiropractors are encouraged to publish objective, structured CRs within defined research gaps. Published CRs can inform the design of future research studies with a higher level of clinical relevance and evidence.
\end{abstract}

Keywords: Case reports, Bibliometrics, Literature review, Chiropractic, Spine, Musculoskeletal diseases, Information science

\section{Introduction}

Bibliometrics is a quantitative study of research publications, often using statistical methods. Case reports (CRs), also called clinical CRs, are uncontrolled description of the clinical course of one to five patients $[1,2]$. Some authors distinguish a CR from a case study, the latter of which has detailed measurements over time [3]. There are few bibliometric reviews of chiropractic research and these

\footnotetext{
* Correspondence: Robert.Trager@UHhospitals.org

Connor Integrative Health Network, Cleveland Medical Center, 11000 Euclid Ave, Cleveland, OH 44106, USA
}

(c) The Author(s). 2021 Open Access This article is licensed under a Creative Commons Attribution 4.0 International License, which permits use, sharing, adaptation, distribution and reproduction in any medium or format, as long as you give appropriate credit to the original author(s) and the source, provide a link to the Creative Commons licence, and indicate if changes were made. The images or other third party material in this article are included in the article's Creative Commons licence, unless indicated otherwise in a credit line to the material. If material is not included in the article's Creative Commons licence and your intended use is not permitted by statutory regulation or exceeds the permitted use, you will need to obtain permission directly from the copyright holder. To view a copy of this licence, visit http://creativecommons.org/licenses/by/4.0/ The Creative Commons Public Domain Dedication waiver (http://creativecommons.org/publicdomain/zero/1.0/) applies to the data made available in this article, unless otherwise stated in a credit line to the data. nal [4-8]. The most recent and comprehensive bibliometric study of peer-reviewed chiropractic CRs was published in 1993 and identified 318 CRs [9].

Chiropractic CRs typically focus on either diagnosis or treatment of a patient or have an educational focus [10]. Diagnosis-focused CRs illustrate how a chiropractor evaluated or assessed a rare or confusing presentation [10], while treatment-focused CRs document improvement in a patient's condition as objectively as possible [11]. This review includes a fourth category of CRs which describe 
adverse effects of chiropractic care, the inclusion of which will aid in the completeness of the bibliometric analysis.

\section{Chiropractic interest in CRs}

Although few chiropractors conduct research, many are interested in doing so. One United States-based study found that $27 \%$ of chiropractic students planned on conducting and publishing some form of research [12], and a 2011 survey of the American Chiropractic Association members found that $60 \%$ reported an interest in conducting research [13]. Despite this interest, only about $2-6 \%$ of chiropractors internationally have published or are engaged in research activities [14-16]. Notwithstanding, two reviews specific to chiropractic journals found that CRs were the most frequently published form of chiropractic research $[5,6]$ and thus may serve as an entry point into research for chiropractors.

Accordingly, multiple chiropractic editorials and commentaries have encouraged students and clinicians to publish CRs [8, 11, 17-25]. These and other publications have provided detailed instructions for chiropractors on how to write CRs $[8,10,11,26-29]$. Authors promoting chiropractic CRs have described motivations to publish CRs that are more specific to the profession which include:

- To increase the chiropractic research database $[10$, 19, 27]

- To increase awareness of chiropractic in the scientific and healthcare community [19]

- To improve inter-professional relationships [19]

- To stimulate intra-professional collaborations [22]

- Important clinical observations are going unpublished [22] or treatment effects only have anecdotal support $[9,11,30]$

- To present the case management of nonmusculoskeletal, non-spinal disorders $[17,18]$

- To focus on populations with a limited research base such as pediatric patients $[18,25]$ and pregnant women [25]

- To help other clinicians with similar cases $[11,18$, 21, 22, 25]

\section{Strengths of this review}

To our knowledge, no prior studies have subcategorized a broad range of chiropractic CRs or investigated predictors of chiropractic $\mathrm{CR}$ citation rates.

\section{Purpose of this review}

The aims of this review are to:

(1) Identify trends and gaps in the research for chiropractic CRs by examining ICD-10 disease category, patient age, topic being case management or adverse effects, focus being spinal or non-spinal, journal type, and integrative authorship.

(2) Summarize citation data for chiropractic CRs with reference to the above listed variables and title metrics.

(3) Perform a multiple logistic regression to identify independent variables associated with greater citations of chiropractic CRs.

\section{Methods}

\section{Search strategy}

Test searches were conducted using PubMed, Microsoft Academic Search, the Index to Chiropractic Literature, EbscoHost, Google Scholar, and Google Scholar using Harzing's Publish or Perish 7 (Tarma Software Research Ltd. $\left.{ }^{\circ}\right)$ to refine the search terms and identify the most accurate and time-saving search strategy. Prior researchers have recommended searching both PubMed/MEDLINE ${ }^{\circ}$ and a chiropractic database (ICL or MANTIS/Chirolars) when conducting chiropractic research because no single database will return all relevant results [31].

In test searches, PubMed returned fewer CRs than expected based on the amount indexed in ICL. Certain CRs that appeared in ICL, but not the PubMed test searches, could be secondarily identified on PubMed by directly searching for the CR title. Conversely, there were CRs in PubMed that did not appear in ICL, such as those published in general medical journals, CR journals, or physical therapy journals.

A preliminary search of EBSCOhost was performed to compare the number of CRs relative to other health disciplines and these CRs were not screened for inclusion into the review. This database enables sorting CRs by specialty. Using the "Advanced Search" options, under "Publication Type" the option "Case Study" was selected (which includes CRs), and results were searched for each category under the "Special Interest" section on 8/25/2020.

Ultimately, three databases were searched for inclusion of CRs into this review: PubMed, ICL, and Google Scholar (Table 1). Search results were downloaded to comma-separated value files and combined into a Microsoft Excel workbook. Articles excluded with specific reasons were recorded in a separate sheet.

The search of ICL was performed to identify PubMedindexed CRs that were not found in the initial PubMed search. The advanced search function was set to Article type: "Case report," and "Peer Reviewed articles." Articles were included provided they were indexed on PubMed and met the other selection criteria.

\section{Selection criteria}

A broad range of types of CRs were included in this study, as described in a prior article [3], including retrospective cases, 
Table 1 Search strategy

\begin{tabular}{llll}
\hline Database & Date of search & Criteria & Initial results \\
\hline Index to chiropractic literature (ICL) & $10 / 30 / 2020$ & Article type: Case report, Peer Reviewed & 2204 \\
PubMed & $10 / 30 / 2020$ & $\begin{array}{l}\text { ((chiropract*[Title/Abstract]) OR (chiropract*[Affiliation])) } \\
\text { OR (chiropractic [MeSH Terms]) }\end{array}$ & 772 \\
& & $\begin{array}{l}\text { Article type: Case report } \\
\text { Keywords: "case report" chiropractic }\end{array}$ & First 100 results screened \\
$\begin{array}{l}\text { Google Scholar using Harzing's } \\
\begin{array}{l}\text { Publish or Perish } \\
\text { EBSCOhost }\end{array}\end{array}$ & $\begin{array}{l}\text { Publication type: Case study } \\
\text { Special interest: Chiropractic Care }\end{array}$ & 609 \\
\hline
\end{tabular}

$\mathrm{N}$-of- 1 studies, single subject trials, and case studies, provided they met the selection criteria listed below. The broad range of study descriptions in our inclusion criteria was purposeful and intended to account for variation in terminology used to describe such cases. In addition, the terms "case study" and "case history" map to "case reports" in Medical Subject Headings in PubMed [3] and were identified using the search strategy. Additional inclusion criteria were the reporting of (1) patient age, (2) sex and (3) relation to any aspect of chiropractic diagnosis, treatment, or case management.

Exclusion criteria were studies that had more than 5 patients, non-human subjects, were anatomical-cadaver studies, and mentioned chiropractic but were unrelated to chiropractic diagnosis or management, or the association was unclear. This criterion was necessary as previous research has highlighted that the terms "chiropractor" or "chiropractic manipulation" are often misused in published CRs describing adverse responses to therapies [32, 33]. This review utilized these prior publications to aid in the exclusion of CRs that used inappropriate terminology. Studies that examined the mechanisms of a diagnostic or treatment method on asymptomatic volunteer(s) were also excluded. Utilization of a quality checklist such as the CARE (CAse REports) guidelines [34] was beyond the scope of this review.

PubMed indexing of CRs was a prerequisite in this study as a means of standardizing the selection of CRs. Although there is an overlap of "peer-reviewed" and "PubMed-indexed" CRs, some chiropractic journals publish peer-reviewed CRs that are not PubMed indexed, for example the Journal of Clinical Chiropractic Pediatrics.

\section{ICD-10 category}

Grouping CR disease by ICD-10 blocks [35] (Table 2), also called categories, has been recommended as a means to categorize CRs for further analysis [36]. Case reports were assigned the best-matching ICD-10 category code [37] which was identified by entering the primary CR diagnosis into a search engine [38]. When there was no exact match for a diagnosis, a Google search was performed to find the most applicable ICD-
Table 2 ICD-10 categories used in this bibliometric analysis

\begin{tabular}{|c|c|}
\hline Block & Title \\
\hline $\begin{array}{l}\text { A00- } \\
\text { B99 }\end{array}$ & Certain infectious and parasitic diseases \\
\hline $\begin{array}{l}\text { C00- } \\
\text { D48 }\end{array}$ & Neoplasms \\
\hline $\begin{array}{l}\text { D50- } \\
\text { D89 }\end{array}$ & $\begin{array}{l}\text { Diseases of the blood and blood-forming organs and certain } \\
\text { disorders involving the immune mechanism }\end{array}$ \\
\hline E00-E90 & Endocrine, nutritional and metabolic diseases \\
\hline F00-F99 & Mental and behavioural disorders \\
\hline $\begin{array}{l}\text { G00- } \\
\text { G99 }\end{array}$ & Diseases of the nervous system \\
\hline $\begin{array}{l}\mathrm{H} 00- \\
\mathrm{H} 59\end{array}$ & Diseases of the eye and adnexa \\
\hline $\begin{array}{l}\mathrm{H} 60- \\
\mathrm{H} 95\end{array}$ & Diseases of the ear and mastoid process \\
\hline $100-199$ & Diseases of the circulatory system \\
\hline J00-J99 & Diseases of the respiratory system \\
\hline K00-K93 & Diseases of the digestive system \\
\hline L00-L99 & Diseases of the skin and subcutaneous tissue \\
\hline $\begin{array}{l}\text { M00- } \\
\text { M99 }\end{array}$ & Diseases of the musculoskeletal system and connective tissue \\
\hline $\begin{array}{l}\text { N00- } \\
\text { N99 }\end{array}$ & Diseases of the genitourinary system \\
\hline $\begin{array}{l}\text { O00- } \\
\text { O99 }\end{array}$ & Pregnancy, childbirth and the puerperium \\
\hline P00-P96 & Certain conditions originating in the perinatal period \\
\hline $\begin{array}{l}\text { Q00- } \\
\text { Q99 }\end{array}$ & $\begin{array}{l}\text { Congenital malformations, deformations and chromosomal } \\
\text { abnormalities }\end{array}$ \\
\hline R00-R99 & $\begin{array}{l}\text { Symptoms, signs and abnormal clinical and laboratory } \\
\text { findings, not elsewhere classified }\end{array}$ \\
\hline S00-T98 & $\begin{array}{l}\text { Injury, poisoning and certain other consequences of external } \\
\text { causes }\end{array}$ \\
\hline V01-Y98 & External causes of morbidity and mortality \\
\hline Z00-Z99 & $\begin{array}{l}\text { Factors influencing health status and contact with health } \\
\text { services }\end{array}$ \\
\hline $\begin{array}{l}\text { U00- } \\
\text { U99 }\end{array}$ & Codes for special purposes \\
\hline
\end{tabular}


10 code. When a patient presented with spinal complaint and another systemic complaint, the non-spinal complaint took precedence and was cataloged by ICD10 category. For CRs describing an adverse effect of chiropractic care, the resulting effect was coded (e.g. fracture) rather than the patient's presenting complaint (e.g. headache) or $\mathrm{V}$ code (external causes of morbidity and mortality). For case series with up to 5 patients having heterogeneous ICD-10 diagnoses, the most frequent ICD-10 category was used. Because there is no specific ICD-10 code for cervicogenic vertigo, CRs describing improvement of dizziness or vertigo after spinal manipulation were grouped within H60-H95. Cases describing "sports hernia" relating to tendinopathy were coded in the M00-M99 category, and those relating to a muscle tear in the S00-T98 category.

Publications for each ICD-10 block were grouped by year. These values were then graphed by percentage of publications as well as publication volume. The slope of the resulting trend line was used to identify publication trends, as has been done in prior studies $[39,40]$.

\section{Pediatric cases}

Case reports were defined as pediatric if the described patient(s) were age 16 or younger, to be consistent with the U.S. Food and Drug Administration definition of a pediatric range for research purposes [41]. For CRs with multiple patients, the most common age bracket of pediatric vs. non-pediatric was used. If there were an even number of cases ( 1 or 2 each) of pediatric and nonpediatric, the pediatric determination was given.

\section{Adverse effects vs. case management topic}

Case reports were divided into two topics, (1) case management-type, which included a diagnostic workup, clinical reasoning, or treatment approach, including integrative CRs, and (2) adverse effects, which included missed or delayed diagnoses resulting in an adverse event, or more direct adverse events related to chiropractic care such as treatment-related injury. These data were then graphed by publication year.

\section{Spinal versus non-spinal focus}

Case reports were divided into two groups, (1) those focusing on spine-related or sacrococcygeal-related symptoms and/or treatments, and (2) those that focused on extraspinal conditions, outside of the spine and sacrococcygeal region. Cases of infection, tumors, or other diseases presenting with spine or sacrococcygeal symptoms were considered spine-related. Cases of vertebral artery pathology or abdominal aortic aneurysm causing neck or back pain were considered spine-related. Cases of shoulder and hip pathology in which treatment included spinal manipulation were also considered spinal.
Cases pertaining to rib symptoms or costochondritis that did not involve therapies directed to the costovertebral or costotransverse joints were considered extraspinal.

\section{Citation metrics}

Case report titles were entered into Google Scholar to calculate the total number of citations. This was done manually from $11 / 2 / 2020-11 / 3 / 2020$. Citations per year were calculated using the formula [citations/(2020-(publication year))] as has been done in other studies [42]. Citation metrics were used from Google Scholar as opposed to another database (such as PubMed) because a larger scope of citation data was preferred to thoroughly examine the overall citation impact of CRs. Google Scholar records citations from a broader range of sources including the grey literature as well as book citations, and finds nearly all citations identified by Web of Science and Scopus [43].

\section{Journal metrics}

Journal names were extracted from the database of selected CRs, sorted alphabetically, and duplicates were removed. Journals were cataloged using a code based on the focus of the journal, which was chosen based on the journal website description and/or mission statement. This system grouped journals into the following categories: medical, chiropractic or alternative and complementary medicine, radiology, physical therapy, integrative, $\mathrm{CR}$, dental, and other. Neurology, surgery, and family medicine journals were cataloged as medical journals. Neuroradiolgy and diagnostic ultrasound journals were grouped with radiology journals. Journal $\mathrm{H}$-index values were identified using SCImago Journal \& Country Rank [44]. This value correlates with the Impact Factor (IF) and SCImago Journal Rank indicator (SJR) [45] and was used because certain journals did not have an assigned SJR or IF, while the $\mathrm{H}$-index is freely available and can be easily found or calculated [46].

Author names were extracted from the database of selected CRs by delimiting to surname and initial(s), and duplicates were deleted. Some author names had multiple variations which was manually corrected (e.g. Chu ECP and Chu EC). Precautions were taken to avoid combining distinct authors (e.g. Jocelyn Cox and James M. Cox).

Further data were gathered for authors publishing in the top ten list of publication volume. Author $\mathrm{H}$-indices were identified on 11/2/2020 using the authors' Google Scholar profile. When this was not available, the author name was searched using Google Scholar via Harzing's Publish or Perish tool with the additional keyword "chiropractic," as these authors had a chiropractic degree or affiliation. Affiliations were extracted from the CR abstract or full-text. 


\section{Integration metrics}

Author degrees were identified for all non-chiropractic authors by searching the full-text of the CR, crossreferencing the author name with other publications, ResearchGate, ICL, or the researcher's website or academic institution. Authors with a medical degree, but no identifiable specialty were recorded as having an "unlisted specialty." In instances where an author obtained a non-chiropractic health degree after the CR publication date, the degree was not listed.

Case reports were recorded as having integrated authorship or single-discipline authorship. To be considered "integrated," authors had to have different health care-related degrees related to patient care. These included medical and osteopathic degrees as well as allied health professions (e.g. physical therapy, nursing). A $\mathrm{PhD}$ author was not considered integrated for the purposes of this review. Case reports by a single author with dual degrees (e.g. DC and MD) were not considered integrated. Multi-author papers with at least one DC and a DC author who had an additional degree such as an RN or MD were considered integrated.

\section{Title metrics}

The number of words and presence of a colon punctuation in each CR title was recorded using Excel counting formulas. Title length and colon punctuation has been identified by prior research to impact citation metrics [47]. Case reports were denoted that used the word stem "case" in the title or any of its derivations including "cases," "case study," or "case report," a measure based on the CARE guidelines [34].

\section{Keywords}

A key phrase finder [48] was used to identify occurrences of common 2-word phrases, to further clarify CR topic and focus.

\section{Logistic regression}

Bivariate logistic regression was performed using GNU PSPP Statistical Analysis Software version 1.0.1. Regression is recommended as the most powerful method of identifying variables affecting article citations [49]. Logistic regression can be used when the distribution of citations is non-normal, to predict papers belonging to a highly cited group [49]. A cutoff $p$-value of 0.05 was used to denote statistical significance.

Prior to logistic regression, testing was performed for bivariate correlation using a two-tailed Pearson correlation matrix to identify strongly associated variables. None of the variables had a correlation coefficient of 0.7 or higher, except citations and citations per year (0.7, $p<0.001$ ), which were analyzed in separate regression models. In addition, the number of (1) total citations and (2) citations per year were tested for a normal distribution by creating a histogram and by using the Kolmogorov-Smirnov test, which yielded an Asymp. sig (2tailed) of $<0.001$ for both, indicating a non-normal distribution.

Prior research on citation impact has recommended comparing the number of citations to the median value [50]. Other research has suggested using citations per year rather than total citations, to adjust for differences in publication year [42]. We used two models with a different independent variable for each: $(1)>7$ total citations ( $>$ median value), and $(2)>0.6$ citations per year ( $>$ median value). Odds ratios (ORs) with confidence intervals were calculated for each variable.

The following covariates were included in the logistic regression: ICD-10 category, pediatric subject, adverse effect or co-management topic, spinal or non-spinal focus, journal type, integrative authorship, and title metrics including presence of a colon (:), presence of the stem "case," and number of words $>11$.

\section{Results \\ Search results}

The search strategy identified 3076 records which was reduced to 1176 after the removal of duplicates and application of selection criteria (Fig. 1). The final list of CRs and those excluded by screening are available upon request.

There were fewer chiropractic CRs relative to other health disciplines or special interests as indexed by EBSCOhost (Fig. 2). For example, chiropractic CRs were outnumbered by pediatric care CRs by a factor of 25:1. This comparison had limitations in that EBSCOhost does not provide a comprehensive list of healthcare specialties, some chiropractic-authored CRs could have been categorized under physical therapy or other special interests, and this database returned fewer chiropractic CRs than PubMed or ICL.

\section{ICD-10 category}

Diseases of the musculoskeletal system and connective tissue (M00-M99) had the greatest volume of CRs (Fig. 3), representing $37.7 \%$ of identified CRs. Consistent with this finding was that the most common 2-word phrases had musculoskeletal associations including "back pain" (87 occurrences), "low back" (70), and "cervical spine" (46). The next most common phrase was "vertebral artery" (37 occurrences) which belonged to Diseases of the circulatory system (I00-199). There were no CRs in the ICD-10 blocks V01-Y98, Z00-Z99, and U00-U99.

Certain conditions originating in the perinatal period (P00-P96) were represented by four CRs, the least of any category, with the first published in 1993, describing treatment for Erb's palsy [51]. Others in this category 


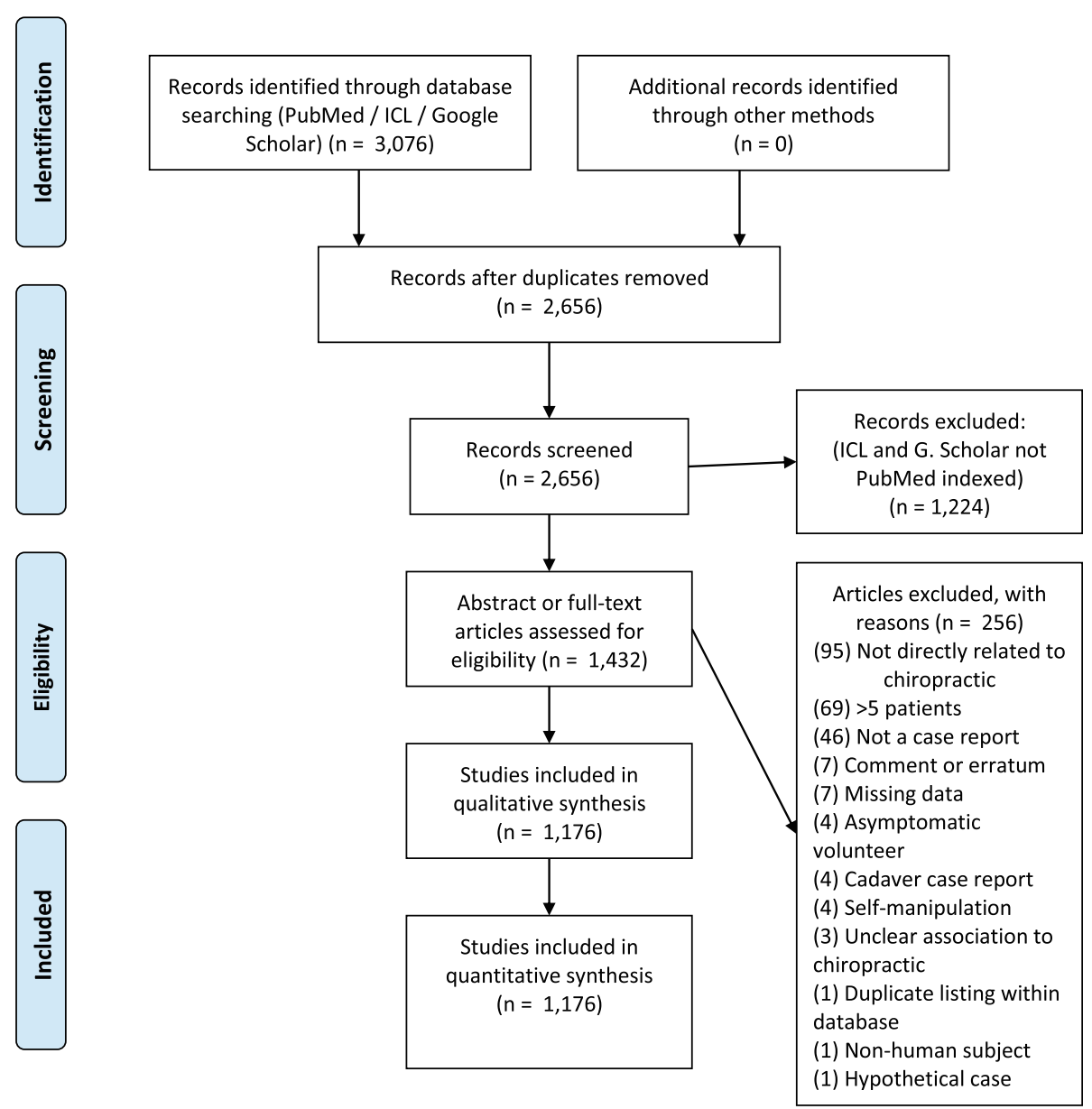

Fig. 1 Preferred Reporting Items for Systematic Reviews and Meta-Analyses (PRISMA) flowchart

described chiropractic management of breast-feeding difficulties [52] and gastroesophageal reflux in an infant [53]. Conditions of pregnancy, childbirth and the puerperium (O00-O99), a related ICD-10 category, likewise had few CRs. The first, published in 1995, was written by nurse midwife and described successful chiropractic manipulation of the pelvis to treat sciatica which developed during labor [54]. Other CRs in this category described the management of pregnancy-related pubic symphysis pain [55], lumbar radiculopathy [56], and meralgia paresthetica [57].

\section{ICD-10 trends}

The rank of publication trends for the top two for case management and adverse effects CRs remained identical when trends for publication volume were analyzed rather than publication percentage, which is what is presented.

The ICD-10 categories with the greatest positive publication trend for case management CRs were Musculoskeletal and connective tissue diseases (M00-M99), followed by Injury, poisoning and certain other consequences of external causes (S00-T98) and Diseases of the nervous system (G00-G99) (Table 3). These categories contain neuromusculoskeletal diagnoses, including spinal pain and radiculopathy (M codes), myelopathy ( $\mathrm{G}$ codes) and sprains and strains (S00-T98).

Additional trends were identified for case management CRs with the highest citation rate since 2015. Musculoskeletal and connective tissue (M00-M99) CRs included an integrative series describing platelet rich plasma injections for sacroiliac joint instability [58], and CRs describing the Chiropractic BioPhysics ${ }^{\circ}$ methods for posture [59], cervical whiplash [60], and scoliosis [61]. Diseases of the nervous system (G00-G99) CRs described management of postoperative spinal arachnoiditis [62], rehabilitative techniques for a patient with posterior cortical atrophy [63], and integrative management of an incomplete cervical spinal cord injury [64]. Injury, poisoning and certain other consequences of external causes (S00-T98) CRs included multidisciplinary management of inguinal/abdominal muscle strains in a 


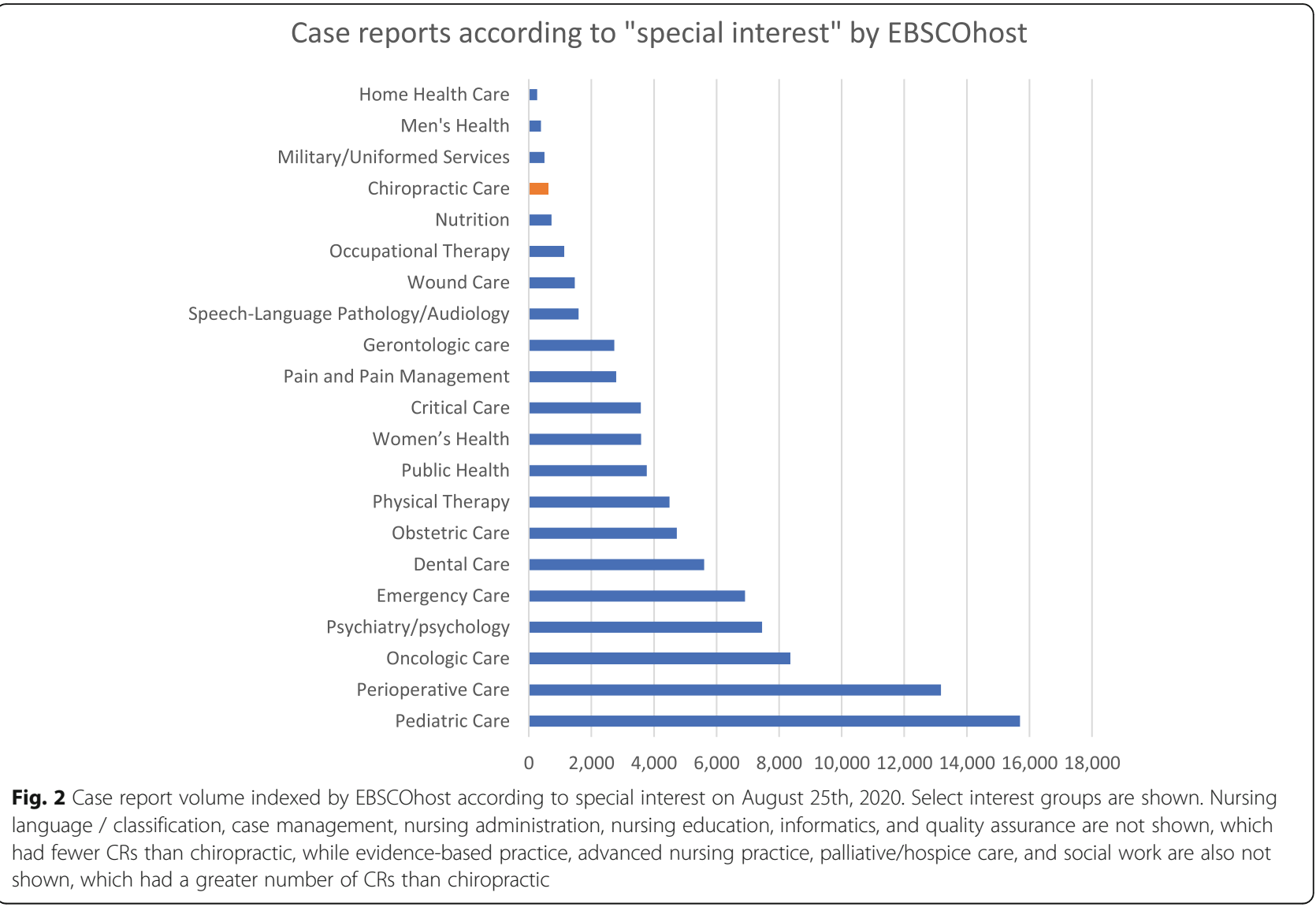

hockey player [65], soft tissue therapy post knee-surgery [66], and diagnostic ultrasonography for lateral ankle injury [67].

Case management CRs in the fourth-fastest growing category, Diseases of the circulatory system (I00-I99), began with the first publication in 1986 [68], with the yearly volume peaking in 2014. Examples include CRs in which chiropractors suspected and referred patients with vertebral artery dissection [69-71], ischemic stroke [72], hemorrhagic stroke [73], upper [74, 75] and lower [76, 77] extremity deep vein thrombosis, abdominal aortic aneurysm [68, 78-81], intracranial aneurysm [82],

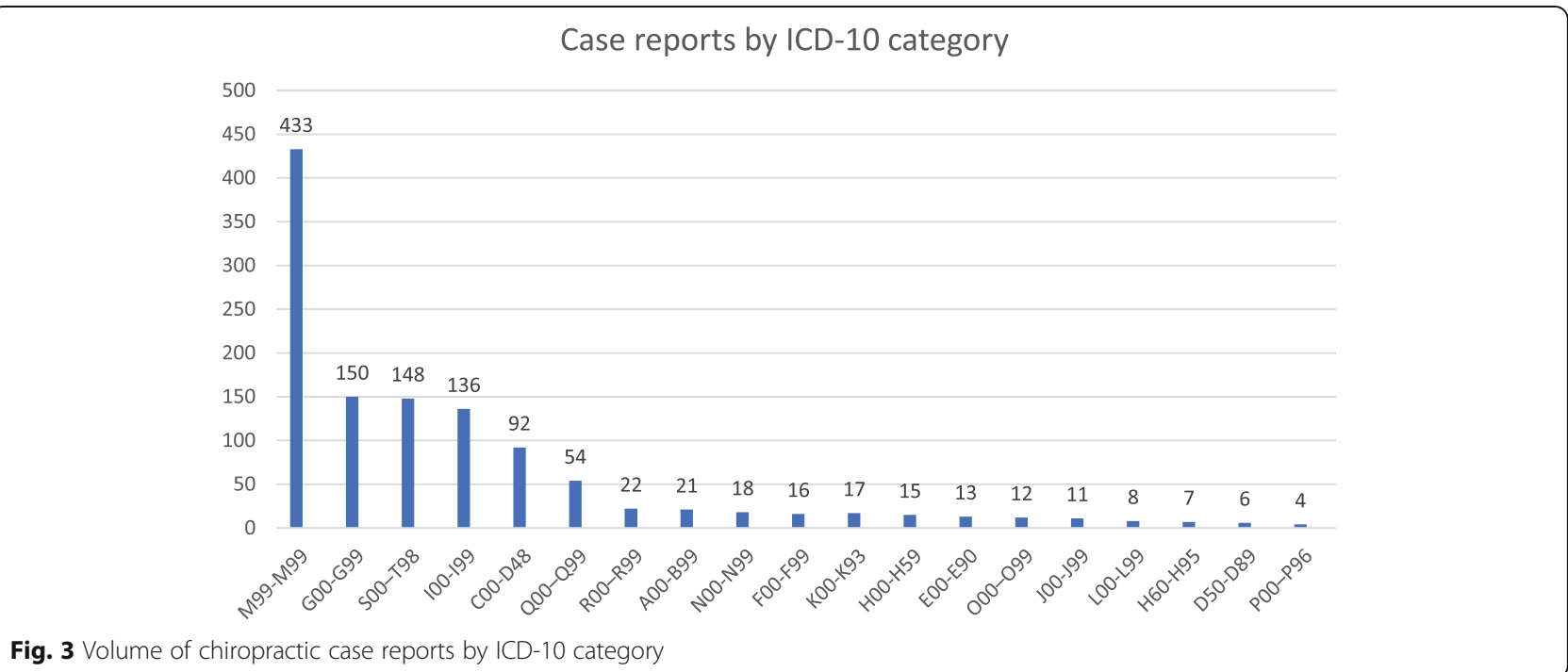

Fig. 3 Volume of chiropractic case reports by ICD-10 category 
Table 3 Trend in ICD-10 category grouped by CR topic, as a percentage of total articles in each respective topic

\begin{tabular}{llllll}
\hline Case management & & & \multicolumn{2}{l}{ Adverse effect } \\
\cline { 1 - 2 } Block & Slope & & Rank & Block & Slope \\
\hline M99-M99 & 0.0049 & 1 & S00-T98 & 0.0039 \\
S00-T98 & 0.0027 & 2 & G00-G99 & 0.0036 \\
G00-G99 & 0.0020 & 3 & H00-H59 & 0.0015 \\
I00-I99 & 0.0013 & 4 & C00-D48 & 0.0009 \\
F00-F99 & 0.0007 & 5 & L00-L99 & 0.0006 \\
K00-K93 & 0.0006 & 6 & O00-O99 & 0.0005 \\
R00-R99 & 0.0005 & 7 & K00-K93 & 0.0002 \\
O00-O99 & 0.0005 & 8 & E00-E90 & 0.0001 \\
L00-L99 & 0.0004 & 9 & D50-D89 & 0.0000 \\
A00-B99 & 0.0003 & 10 & H60-H95 & 0.0000 \\
N00-N99 & 0.0003 & 11 & N00-N99 & 0.0000 \\
P00-P96 & 0.0001 & 12 & P00-P96 & 0.0000 \\
J00-J99 & 0.0001 & 13 & R00-R99 & 0.0000 \\
Q00-Q99 & 0.0000 & 14 & A00-B99 & -0.0002 \\
D50-D89 & 0.0000 & 15 & Q00-Q99 & -0.0002 \\
H00-H59 & 0.0000 & 16 & F00-F99 & -0.0011 \\
C00-D48 & -0.0005 & 17 & M99-M99 & -0.0014 \\
E00-E90 & -0.0014 & 18 & J00-J99 & -0.0014 \\
H60-H95 & -0.0026 & 19 & I00-199 & -0.0040 \\
\hline
\end{tabular}

popliteal aneurysm [83], myocardial infarction [84] and subdural hematoma [85].

The ICD-10 categories with the greatest positive publication trend in the adverse effect topic were Injury, poisoning and certain other consequences of external causes (S00-T98) and Diseases of the nervous system (G00-G99). In contrast, Diseases of the circulatory system (I00-I99) had the greatest negative trend.

\section{Pediatric cases}

Only 138 CRs (12\%) included a pediatric subject. There was an " $M$ "-shaped pattern of both the volume and percentage of pediatric CRs with peaks in 1989 and 2010.

\section{Adverse vs. case management topic}

There were 187 CRs describing adverse effects and 989 CRs describing case management (Fig. 4). The number of yearly chiropractic case management CRs irrevocably surpassed those describing adverse effects in 1984, and since 1990 has outnumbered adverse effect CRs in a ratio of 6:1, with a mean 28.5 case management CRs per year and 4.6 adverse effect CRs per year since 1990. The greatest yearly volume of chiropractic case management CRs was 53, in 2012. The 5-year mean percentage of adverse effect CRs has decreased from $77 \%$ in 1980 to $17 \%$ in 1990 to $15 \%$ in 2020 .
Spine vs. non-spinal focus

There was an overall gradual decrease in the percentage of spine-related CRs, and conversely, an increase in nonspine-related CRs (Fig. 5). The 5-year mean proportion of spine-related CRs has reduced from $92 \%$ in 1980 to $79 \%$ in 1990 to $68 \%$ in 2020.

\section{Citation metrics}

Analysis of citation data revealed that $89 \%$ of CRs were cited. The median total citations per paper was 7.0, with a mean of $13.0 \pm 20.2$. The median citations per year was 0.6 , with a mean of $0.9 \pm 1.5$. Six of the ten CRs with the greatest citations per year were published since 2010, with each describing case management (Table 4).

\section{Journal metrics}

Chiropractic CRs were published in 186 unique journals. The majority of chiropractic CRs (852 CRs or $72 \%$ of total), regardless of topic or focus, were published in three journals, the Journal of Manipulative and Physiological Therapeutics, the Journal of the Canadian Chiropractic Association, and the Journal of Chiropractic Medicine. Chiropractic journals had published eight adverse effect topic CRs representing $0.9 \%$ of their total CRs while medical journals published 164, representing $85 \%$ of their total CRs. The medical journal with the greatest number of published chiropractic CRs was Neurology, which published six, all of which described adverse effects.

Prior to the 1980 s most chiropractic CRs were published in medical journals, with $79 \%$ of these CRs describing an adverse effect. From 1984 to 2020 most chiropractic CRs were published in chiropractic-focus journals (Fig. 6). Publication in chiropractic journals has reduced as a percentage of total CRs since 2017 (70\% in $2017,62 \%$ in $2018,59 \%$ in 2019 ).

Since 2015, three journal types have emerged with increasing $\mathrm{CR}$ volume: physical therapy, integrative medicine, and dedicated CR journals (Fig. 7). From 2018 to 2020, these have combined to publish up to $28 \%$ of chiropractic CRs. The most published physical therapy journal was $J$ Phys Ther Sci (13 of 16 in that journal type), integrative medicine was EXPLORE (NY) (4 of 11), and CR journal was tied between AME Case Rep and BMJ Case Rep (3 each of 9).

$\mathrm{H}$-indices were readily available using SCImago for 163 out of 186 Journals. The remainder were calculated via Google Scholar using Harzing's Publish or Perish.

\section{Author metrics}

There were 2191 unique authors of CRs with a mean $1.5 \pm 1.9$ and median of $1 \mathrm{CR}$ per author. The most prolific authors were affiliated with chiropractic schools in the USA, Canada, and Australia (Table 5). 


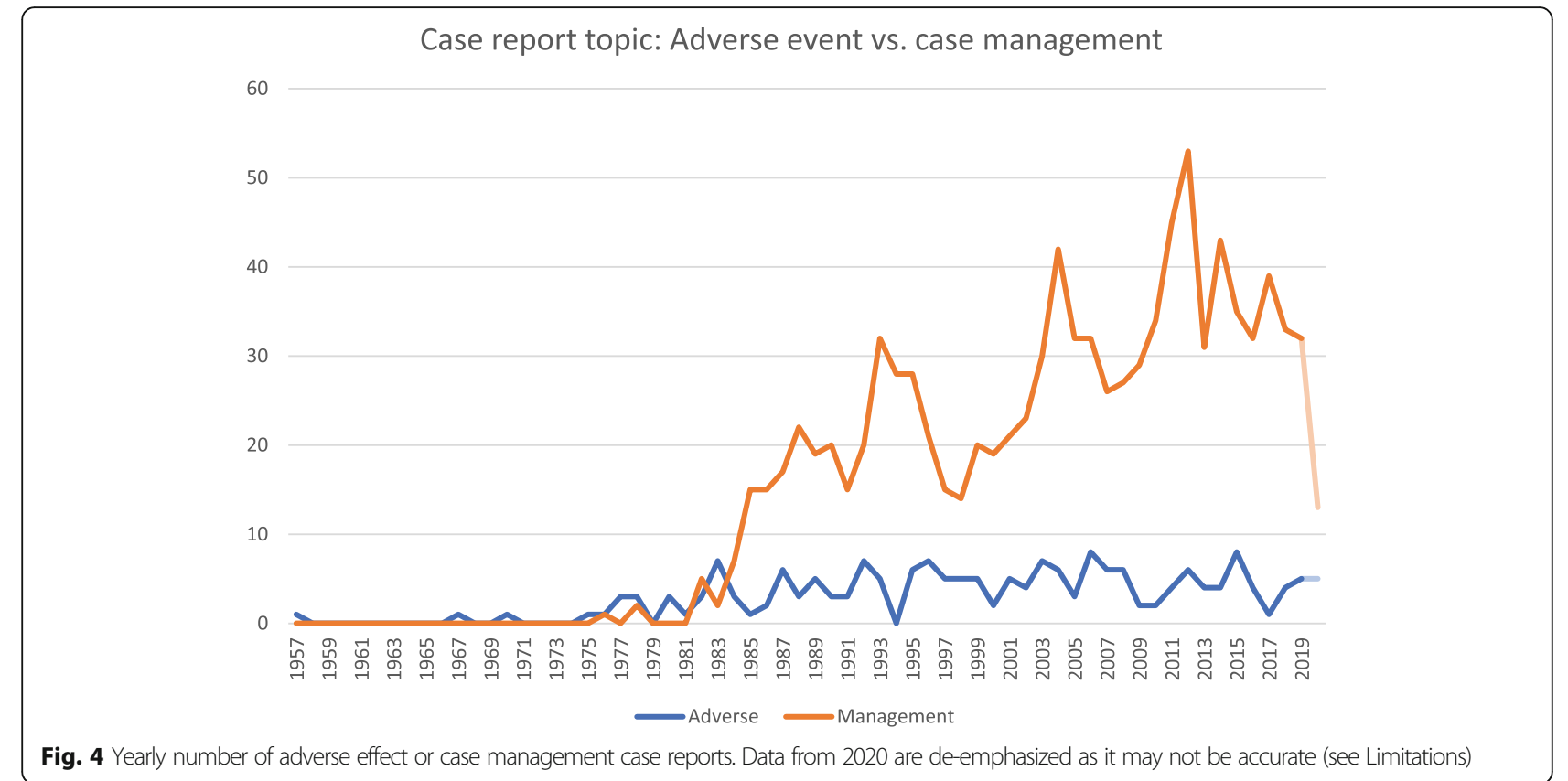

\section{Integration metrics}

There were 158 CRs with integrative authorship teams which represented $13 \%$ of all CRs. Most of these described case management type CRs ( $98 \%$ of integrative CRs), while three described adverse effects (2\%) [86-88]. The most frequent integrative teams included a chiropractor with another author specializing in orthopedic surgery, radiology, physical therapy, or nursing (Fig. 8). There were several allied health professions and medical specialties not represented including allergy and immunology, anatomic and clinical pathology, cardiology, dermatology, gastroenterology, hematology, infectious disease, oncology, pediatrics, plastic surgery, psychiatry, and urology.

There was an overall increase in CRs with integrative authorship since the first was published in 1984 [89]. There was a temporary downturn between 1995 and

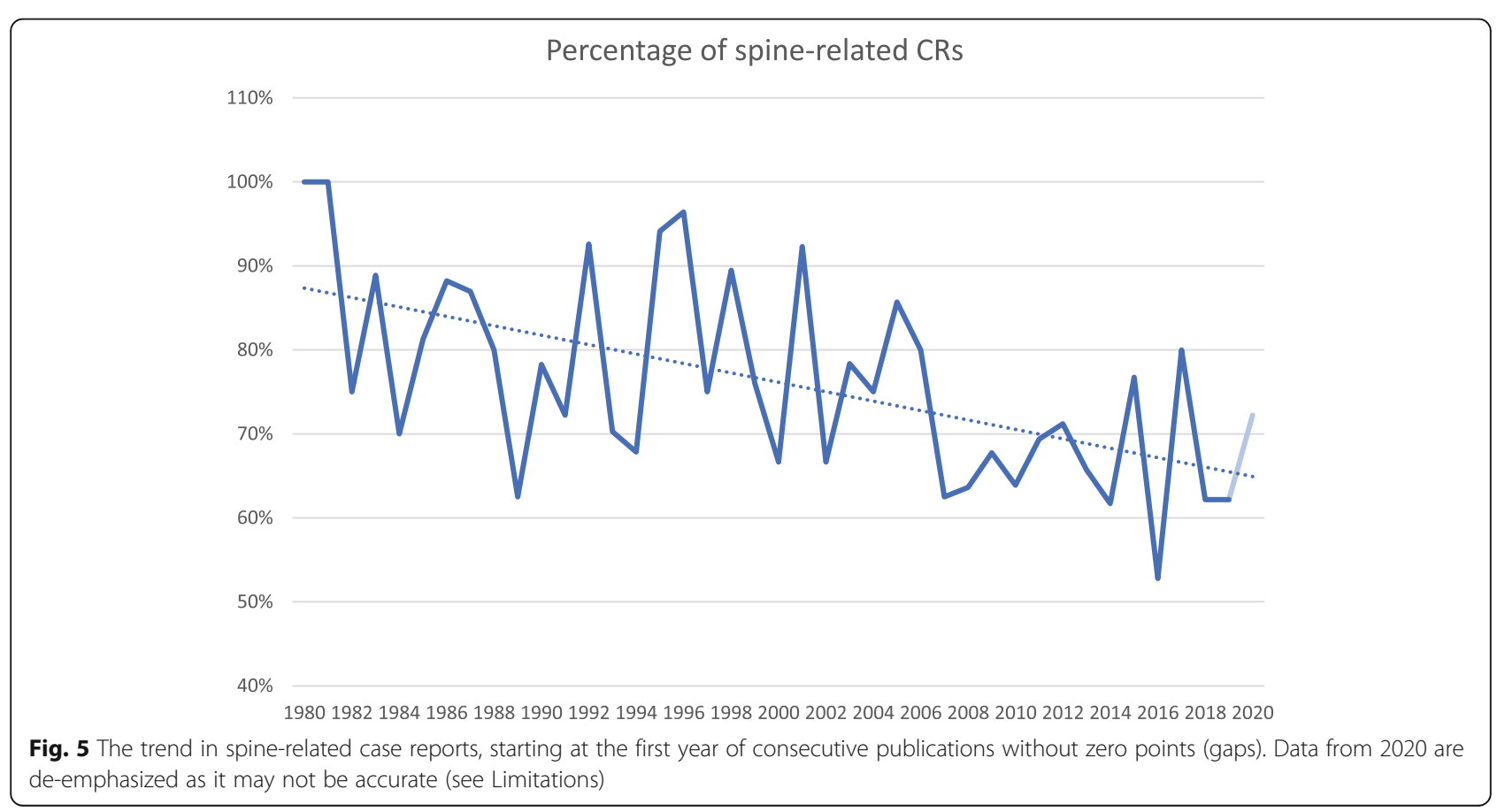


Table 4 The ten most frequently cited case reports

\begin{tabular}{|c|c|c|c|c|}
\hline Author & Year & Title & $\begin{array}{l}\text { Citations } \\
\text { per year }\end{array}$ & Journal \\
\hline $\begin{array}{l}\text { Furmli } \\
\text { et al }\end{array}$ & 2018 & $\begin{array}{l}\text { Therapeutic use of intermittent fasting for people with type } 2 \text { diabetes as an alternative to } \\
\text { insulin }\end{array}$ & 27.0 & BMJ Case Rep \\
\hline Rubin & 2010 & $\begin{array}{l}\text { Triad of spinal pain, spinal joint dysfunction, and extremity pain in } 4 \text { pediatric cases of "Wii-itis": } \\
\text { A twenty-first century pediatric condition }\end{array}$ & 20.5 & J Chiropr Med \\
\hline Moore & 2004 & Upper crossed syndrome and its relationship to cervicogenic headache & 12.8 & $\begin{array}{l}\text { J Manipulative } \\
\text { Physiol Ther }\end{array}$ \\
\hline Blum & 2002 & Chiropractic and pilates therapy for the treatment of adult scoliosis & 12.4 & $\begin{array}{l}\text { J Manipulative } \\
\text { Physiol Ther }\end{array}$ \\
\hline $\begin{array}{l}\text { Marshall } \\
\text { et al }\end{array}$ & 2015 & The role of the cervical spine in post-concussion syndrome & 10.4 & Phys Sportsmed \\
\hline Hammer & 2008 & The effect of mechanical load on degenerated soft tissue & 9.7 & J Bodyw Mov Ther \\
\hline Ko et al & 2017 & Case series of ultrasound-guided platelet-rich plasma injections for sacroiliac joint dysfunction & 8.7 & $\begin{array}{l}\text { J Back } \\
\text { Musculoskelet } \\
\text { Rehabil }\end{array}$ \\
\hline $\begin{array}{l}\text { Ferguson } \\
\text { et al }\end{array}$ & 2014 & A case of early sports specialization in an adolescent athlete & 8.5 & $\begin{array}{l}\text { J Can Chiropr } \\
\text { Assoc }\end{array}$ \\
\hline $\begin{array}{l}\text { Miners } \\
\text { et al }\end{array}$ & 2011 & $\begin{array}{l}\text { Chronic Achilles tendinopathy: A case study of treatment incorporating active and passive tissue } \\
\text { warm-up, Graston Technique }{ }^{\oplus} \text {, ART }{ }^{\oplus} \text {, eccentric exercise, and cryotherapy }\end{array}$ & 7.8 & $\begin{array}{l}\text { J Can Chiropr } \\
\text { Assoc }\end{array}$ \\
\hline $\begin{array}{l}\text { Hammer } \\
\text { et al }\end{array}$ & 2005 & Treatment of a case of subacute lumbar compartment syndrome using the Graston technique & 6.1 & $\begin{array}{l}\text { J Manipulative } \\
\text { Physiol Ther }\end{array}$ \\
\hline
\end{tabular}

2005 (Fig. 9). The proportion of integrative CRs has not increased since the 1990s. Integrative CRs made up $17 \%$ of CRs from 1990 to 1995, and 17\% from 2015 to 2020.

\section{Title metrics}

The mean number of words in CR titles was $11.7 \pm 4.8$, with a median of 11 , while $52 \%$ of CRs had a colon in the title, and 52\% mentioned "case" in the title.

\section{Logistic regression}

Multiple variables were independent predictors of citation counts (Tables 6 and 7). Case reports dealing with Certain conditions originating in the perinatal period (P00-P96) had 13.2 times the odds of receiving more than the median value (0.6) of citations per year, and 5.4 times the odds of having more than the median value (7) of citations. Certain infectious and parasitic diseases (A00-B99) CRs had 1.6 times the odds of having more than the median value of citations. The

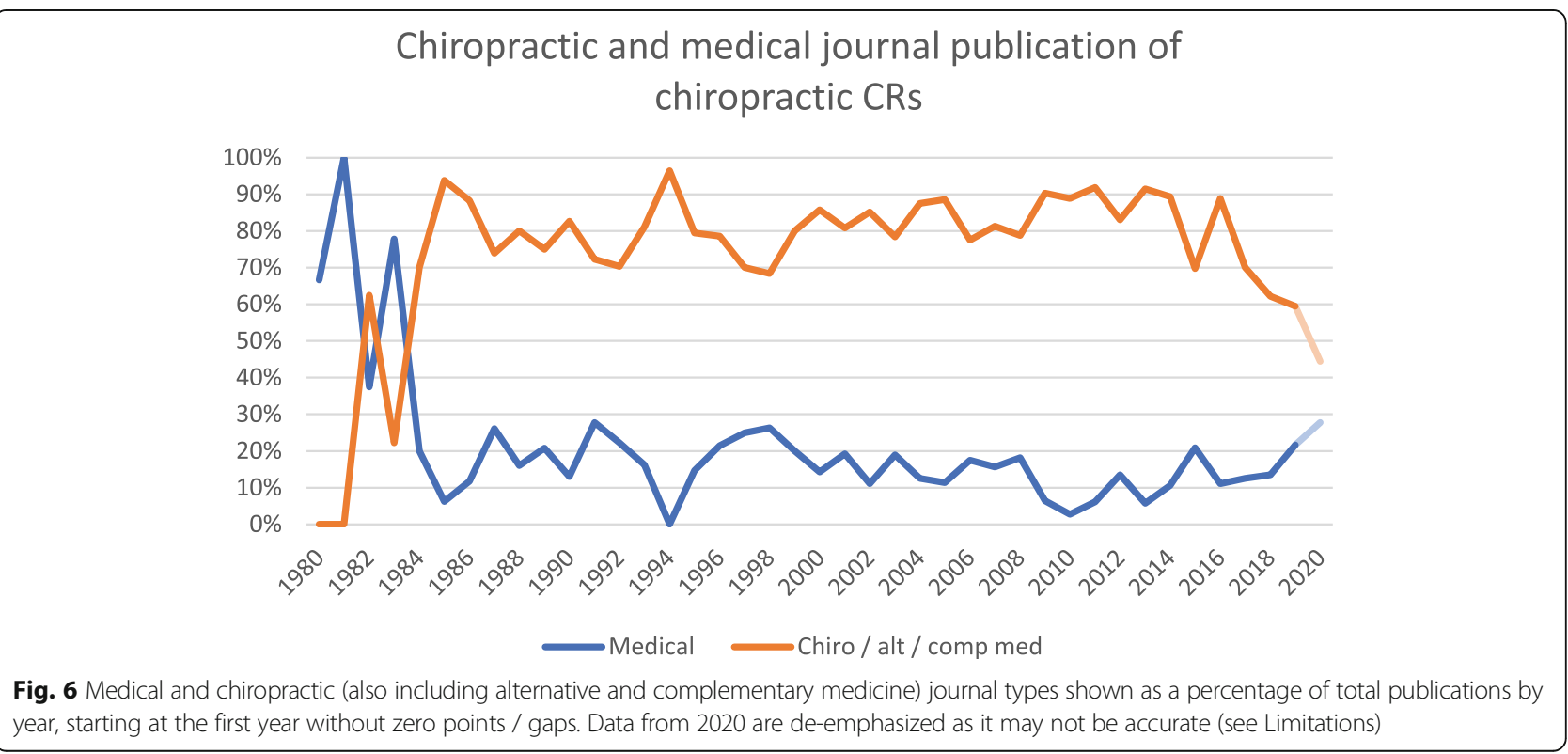




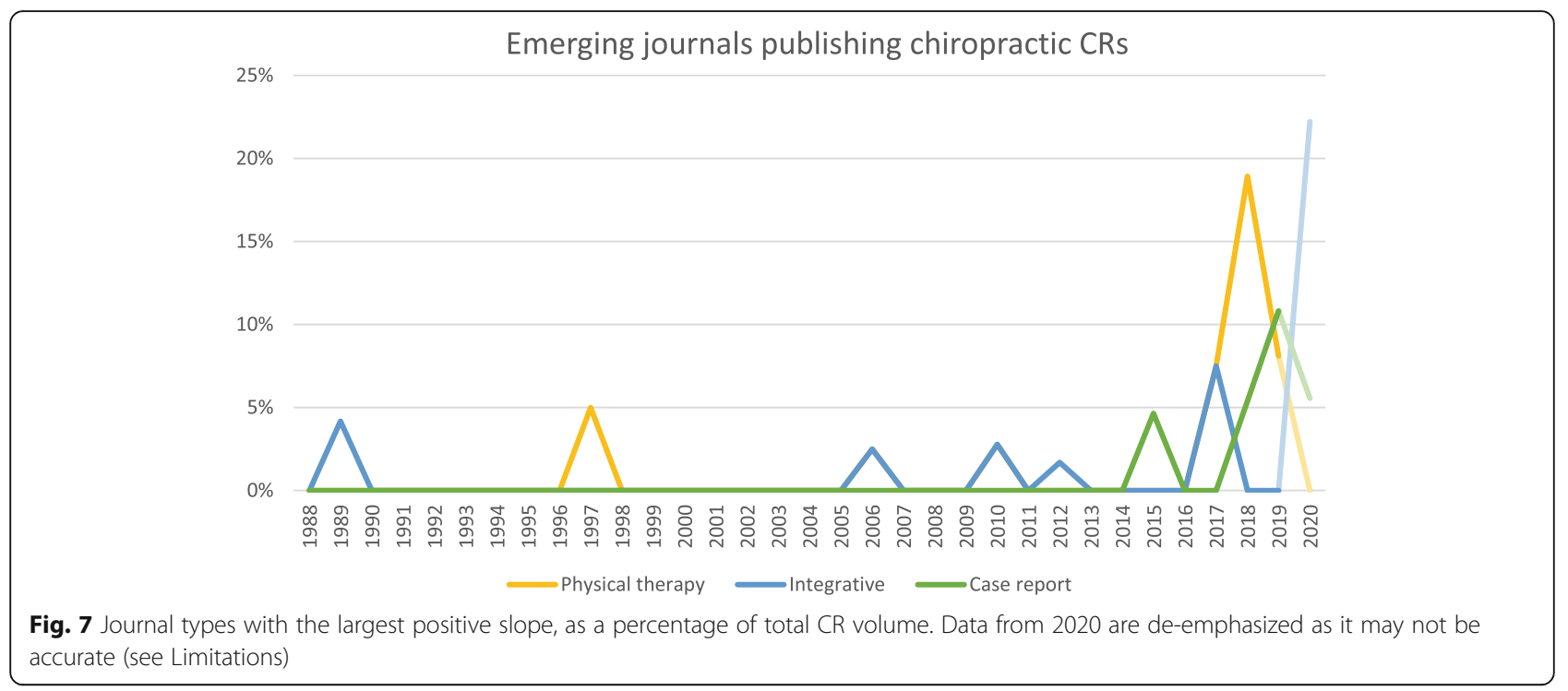

categories Diseases of the blood and blood-forming organs and certain disorders involving the immune mechanism (D50-D89), Neoplasms (C00-D48), and Symptoms, signs and abnormal clinical and laboratory findings, not elsewhere classified (R00-R99) were independent predictors of fewer citations.

Physical therapy (OR 35.9), integrative (OR 24.3), and dental journals (OR 32.3) had greater odds of a citation rate greater than the median value. The title word-stem "case" in the title was a predictor of increased citation rate (OR 1.6) while a lengthy title (>11 words) was a predictor of reduced total citations. Case management topic CRs had greater odds (OR 2.5) of having more citations than the median value, while multidisciplinary authorship was a negative predictor (OR 0.7).

H-index had a negligible odds ratio for affecting citations, while spine focus, having a pediatric subject, and a colon punctuation in the title were not statistically significant predictors of citations.

\section{Discussion \\ Emerging topics \\ Neuromusculoskeletal CRs}

The three categories of chiropractic CRs with the greatest publication volume were also the fastest growing among those with a case-management topic: Diseases of the musculoskeletal system and connective tissue (M00-

Table 5 Most prolific authors of chiropractic case reports

\begin{tabular}{|c|c|c|c|c|c|c|c|}
\hline Authors & $\begin{array}{l}\text { Case } \\
\text { reports }\end{array}$ & $\begin{array}{l}\mathrm{H}- \\
\text { index }\end{array}$ & Country & $\begin{array}{l}\text { CR } \\
\text { Range }\end{array}$ & $\begin{array}{l}\text { CR } \\
\text { citations }\end{array}$ & $\begin{array}{l}\text { CR citations } \\
\text { per year }\end{array}$ & $\begin{array}{l}\text { Affiliations } \\
\text { (in addition to private practice, if present) }\end{array}$ \\
\hline Kettner N & 48 & 27 & USA & $1992-2019$ & 393 & 39 & Logan College of Chiropractic \\
\hline Cassidy JD & 32 & 46 & Canada & 1984-1995 & 157 & 5 & University Hospital, University of Saskatchewan \\
\hline Taylor JA & 18 & 11 & USA & $1990-2013$ & 87 & 11 & $\begin{array}{l}\text { Los Angeles College of ChiropracticNew York Chiropractic } \\
\text { CollegeD'Youville College, Department of Chiropractic }\end{array}$ \\
\hline Alcantara J & 17 & 13 & USA & 1996-2012 & 218 & 14 & $\begin{array}{l}\text { International Chiropractic Pediatric AssociationGonstead } \\
\text { Clinical Studies SocietyPalmer College of Chiropractic West }\end{array}$ \\
\hline Mierau D & 17 & 8 & Canada & 1985-1996 & 41 & 2 & University Hospital, University of Saskatchewan \\
\hline Harrison DE & 17 & 41 & USA & 2004-2019 & 142 & 33 & Chiropractic Biophysics, Non Profit, Inc. \\
\hline Pollard H & 15 & 36 & Australia & $1995-2010$ & 337 & 22 & Macquarie University School of Chiropractic \\
\hline Stern P & 14 & 13 & Canada & 1994-2014 & 184 & 22 & Canadian Memorial Chiropractic College, \\
\hline Chu EC & 13 & 2 & China & $2017-2020$ & 12 & 9 & $\begin{array}{l}\text { New York Chiropractic \& Physiotherapy Centre, New York } \\
\text { Medical Group }\end{array}$ \\
\hline Emary $P$ & 13 & 6 & Canada & 2009-2017 & 55 & 8 & None listed \\
\hline Plaugher G & 13 & 12 & USA & 1993-2004 & 208 & 10 & $\begin{array}{l}\text { Palmer College of Chiropractic WestLife Chiropractic } \\
\text { College West }\end{array}$ \\
\hline Oakley PA & 13 & 10 & Canada & 2017-2019 & 53 & 27 & Chiropractic Biophysics, Non Profit, Inc. \\
\hline
\end{tabular}




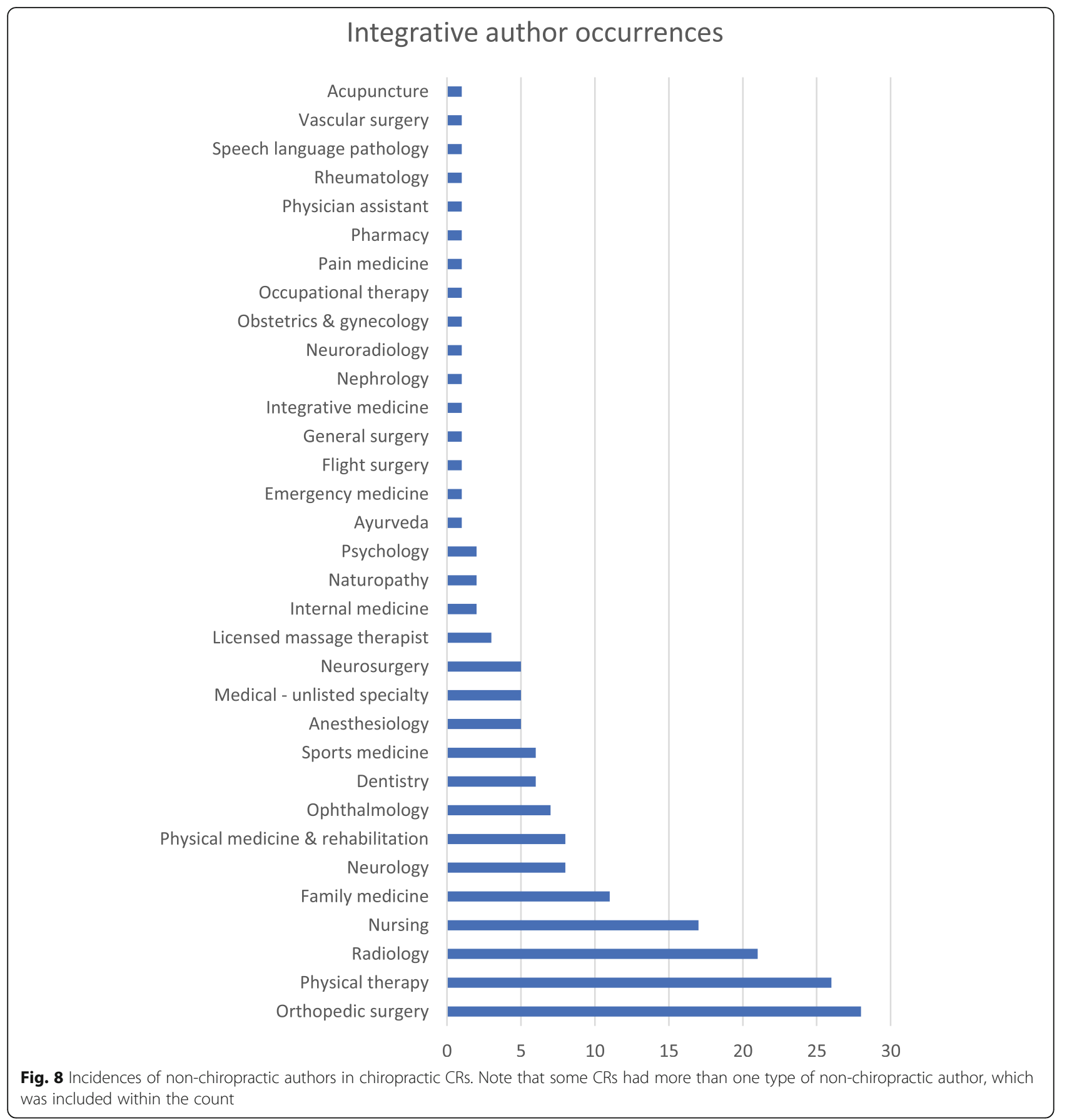

M99), Injury, poisoning and certain other consequences of external causes (S00-T98), and Diseases of the nervous system (G00-G99). According to a 2014 survey, the most common conditions managed by American chiropractors include disorders of the joints, nervous system, and muscles [90], conditions which fit into these ICD-10 categories.

Further analysis of Diseases of the musculoskeletal system and connective tissue (M00-M99) showed that more recent CRs had a sports-medicine or rehabilitative non-spine-related focus. Case reports in Diseases of the nervous system (G00-G99) highlighted unique approaches to management or uncommon presentations of neurological illnesses.

\section{Vascular diagnosis CRs}

There was an increase in CRs describing potentially lifesaving identification of vascular pathology (ICD I00-I99) preceding manual therapy interventions, such as vertebral arterial dissection in-progress [69-71]. Authors of 


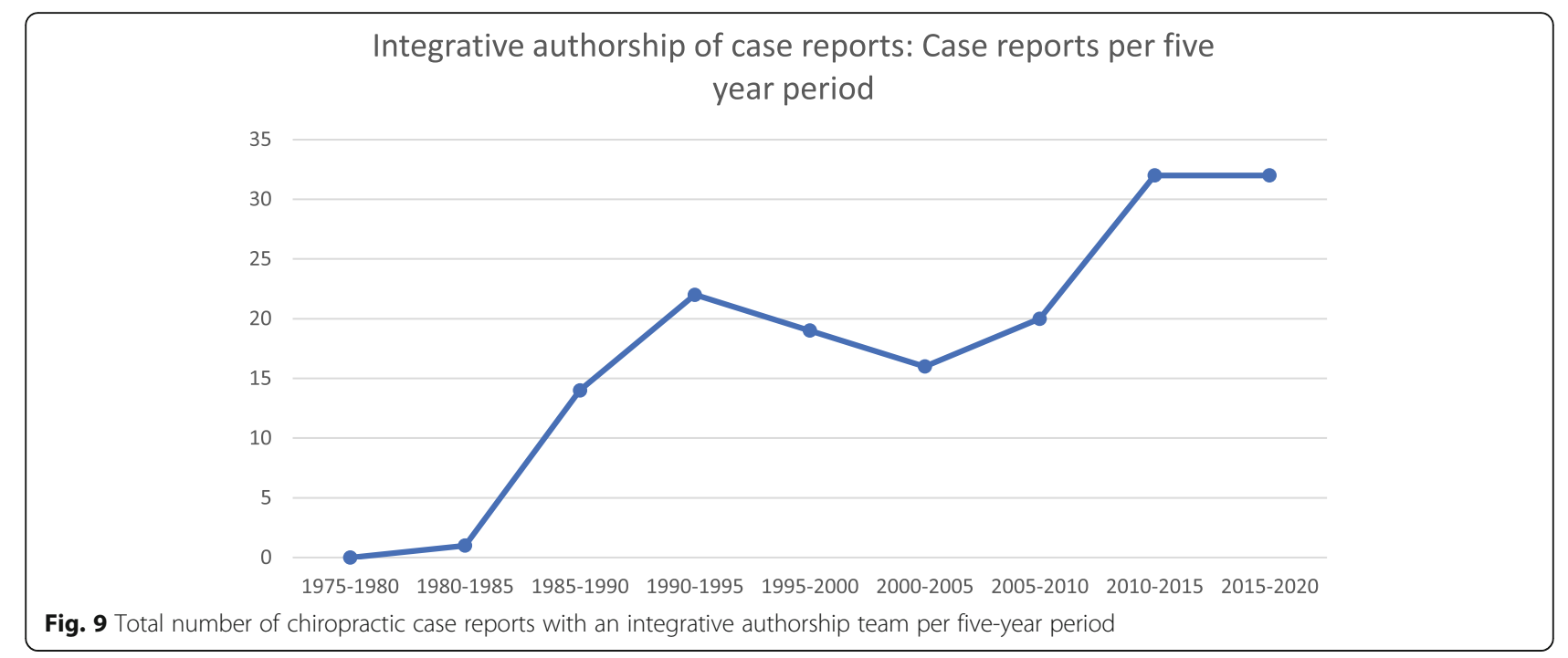

vascular diagnosis CRs pointed out the difficulty in diagnosing vertebrobasilar arterial pathology [69] and inadequacy of provocative physical maneuvers [91]. None of these CRs described the use of the newer Head Impulse, Nystagmus, and Test of Skew (HINTS) examination [92]. In contrast to the emergence of these vascular diagnosis-oriented CRs, adverse effect I00-I99 CRs had the strongest negative publication trend of any ICD-10 category.

A recent systematic review concluded there was no convincing evidence of a link between chiropractic spinal manipulation and cervical arterial dissection, which had been hypothesized in prior studies and adverse effect CRs [93]. Vascular diagnosis CRs provide contextual evidence to support the hypothesis [94] that an epidemiologic association between chiropractic visits and the onset of vascular pathology could be explained by patients presenting to the chiropractic office with pre-existing occult vascularrelated pathology. Ultimately, case-control study designs are better suited to study rare adverse outcomes.

\section{Non-spinal musculoskeletal topics}

Some chiropractic research agendas have prioritized the research of the efficacy of chiropractic care for musculoskeletal conditions outside of the spine, including sportsrelated soft-tissue and extremity disorders $[95,96]$. Of the ten case management CRs in M00-M99 with the highest citation rate, seven described instrument-assisted soft tissue manipulation for treating extremity injuries [97-103], six of which involved athletes. Similarly, in S00-T98, eight of the ten case management CRs with the highest citation rate described sport-related injuries, and only half of these had a spinal focus. Sports medicine appears to be an emerging area of chiropractic CRs.

\section{Concussion-related disorders}

There were seven CRs describing post-concussion syndrome or traumatic brain injury, all of which were published since 2014 [104-110]. Because there is no unifying ICD-10 group for these diagnoses, these CRs were split into Diseases of the nervous system (G00-

Table 6 Logistic regression for citations per year over the median value (>0.6)

\begin{tabular}{lll}
\hline Variable & Odds ratio $(\mathbf{9 5 \%} \mathrm{Cl})$ & $\boldsymbol{p}$-value \\
\hline$>11$ words in title & $0.61(0.47-0.78)$ & $<0.001$ \\
H-index & $1.01(1.00-1.01)$ & $<0.001$ \\
ICD-10 category & & \\
ICD M00-M99 & (reference) & 0.046 \\
ICD D50-D89 & $0.56(0.32-0.99)$ & 0.004 \\
ICD P00-P96 & $13.22(2.26-77.34)$ & \\
Journal type & & 0.016 \\
Chiropractic and alternative / complementary medicine & $($ reference) & 0.025 \\
Physical therapy & $35.89(1.96-656.19)$ & 0.020 \\
Integrative & $24.26(1.50-393.54)$ & $32.26(1.71-606.99)$ \\
Dental & & \\
\hline
\end{tabular}


Table 7 Logistic regression for total citations over the median value $(>7)$

\begin{tabular}{lll}
\hline Variable & $\begin{array}{l}\text { Odds ratio } \\
\mathbf{( 9 5 \% ~ C l )}\end{array}$ & $\boldsymbol{p}$-value \\
\hline H-index & $1.02(1.01-1.02)$ & $<0.001$ \\
"case" word stem in title & $1.55(1.06-2.27)$ & 0.025 \\
$\begin{array}{l}\text { Multidisciplinary authorship } \\
\text { (Ref. single-discipline) }\end{array}$ & $0.66(0.45-0.98)$ & 0.037 \\
$\begin{array}{l}\text { Case management topic } \\
\text { (Ref. adverse effect) }\end{array}$ & $2.53(1.11-5.77)$ & 0.027 \\
ICD-10 category & & \\
ICD M00-M99 & & \\
ICD A00-B99 & $($ reference) & \\
ICD C00-D48 & $1.55(1.03-2.34)$ & 0.035 \\
ICD P00-P96 & $0.23(0.07-0.78)$ & 0.018 \\
ICD R00-R99 & $5.44(1.20-24.65)$ & 0.028 \\
\hline
\end{tabular}

G99, 1 CR), Injury, poisoning and certain other consequences of external causes (S00-T98, 2 CRs), and Mental and behavioural disorders (F00-F99, 4 CRs). A test of recoding these under F00-F99 did not change the position of F00-F99 from the 5th fastest growing ICD-10 category.

\section{Gaps in the literature}

\section{Commonly seen conditions}

Comparison of CR data to a survey from 2014 [90] revealed a discrepancy between the ICD-10 publication volumes and frequency of diagnoses seen by American chiropractors (Table 8). Certain conditions seen on a monthly basis had a low publication volume while in contrast, congenital anomalies (Q00-Q99) had a high volume relative to being seen only on a yearly basis [90].

\section{Pregnant women, pediatrics, and infants}

Case management CRs in specific populations including pregnant women, and pediatric patients, including infants, had a low publication volume, represented by ICD-10 categories O00-O99 and P00-P96. One possible explanation is that authors may publish these in nonPubMed indexed journals such as the Journal of Clinical Chiropractic Pediatrics.

\section{Non-musculoskeletal topics}

Non-musculoskeletal ICD-10 topics had a low publication volume. Among these, specific CRs were distinct as having little additional evidence supporting the use of chiropractic spinal manipulation above the CR level. These included gastroesophageal reflux $[53,111]$, constipation [112, 113] and pruritis [114]. In contrast, CRs documenting improvements in asthma post-spinal manipulation may be limited because this topic has been explored by larger study designs including randomized controlled trials [115].

\section{Collaboration in chiropractic}

Multiple international research agendas have prioritized collaborative research activities [95, 116-119]. The increasing publication volume of integrative CRs is an example that this is occurring.

Although integrative authorship was a negative predictor of CR citations in our regression model, there may be less-tangible benefits to multidisciplinary collaboration. Citation tracking of integrative author teams demonstrated that certain teams had cooperated later to co-publish larger studies (Table 9), which were often on different topics. This suggests that an integrative authorship CR may be a gateway to conducting research with a higher level of evidence, irrespective of topic.

\section{Professional development}

Further analysis of the CR database identified multiple chiropractic college presidents who published CRs prior to their presidency, such as Drs. Michael Mestan [120] (New York Chiropractic College), William Morgan [109] (Parker University), William Meeker [121] (Palmer College of Chiropractic), John Scaringe [122] (Southern California University of Health Sciences), as well as top researchers in the field (e.g. Simon French) [123], and developers of postgraduate training (e.g. Donald Murphy) [124].

\section{Future use of CRs by chiropractors}

Case reports are more accessible, achievable, and do not require advanced research skills compared to more sophisticated research designs [125]. In this sense CRs may be more attractive to chiropractic practitioners without an additional research degree or training [21, 28]. Writing a CR has become straightforward due to the CARE guidelines, which act as a checklist to ensure relevant information is included in a CR [34]. Adherence to CARE guidelines may also increase the impact of chiropractic CRs, as having "case" in the title independently predicted a greater number of citations in our regression model.

Case reports can serve as a foundation for larger studies such as cohort studies and trials which ultimately improve patient care [125]. Synthesis or review of similar CRs and case series is also possible, which can add to the evidence base from which to make clinical decisionmaking when there is no higher level of evidence available [1]. Examples of prior syntheses incorporating chiropractic CRs include those focusing on nonmusculoskeletal conditions [126], upper extremity conditions [127], and colic [128]. Future syntheses might describe the clinical features of patients presenting to a chiropractic office with a stroke in progress, or the 
Table 8 ICD-10 categories with a discrepancy between CR volume and frequency seen in a chiropractic setting

\begin{tabular}{llll}
\hline ICD-10 Block & CR volume & Example condition(s) & Average frequency seen [90] \\
\hline H60-H95 & 7 & $\cdot$ Vertigo / loss of equilibrium & Monthly \\
E00-E90 & 13 & $\begin{array}{l}\text { - Diabetes / metabolic syndrome } \\
\text { - Nutritional disorder }\end{array}$ & Monthly \\
O00-099 & 12 & $\cdot$ Pregnancy related conditions & Monthly \\
Q00-Q99 & 54 & $\cdot$ Hereditary multiple exostosis & Yearly \\
\hline
\end{tabular}

treatment of coexisting cervical spine disorders in patients with post-concussion syndrome.

It was unclear why certain chiropractors were so prolific in publishing CRs. Future research could involve a survey of $\mathrm{CR}$ authors to determine their motivations for publishing CRs, interest in publishing certain CR topics or diseases, preference of target journal type, opinion towards integrative authorship, and interest in conducting research with larger study designs.

\section{Limitations}

Aside from the title including "case," we did not calculate a quality score for the CARE guidelines rubric, which could have enabled us to investigate temporal changes in the quality of reporting CRs. Older case reports may not have "case report" in the title due to editorial style guidelines. As the CARE guidelines recommending this were only recently introduced, title metrics should be interpreted with caution.
Additional case reports may have been identified by searching more databases such as MANTIS/Chirolars and CINAHL. Due to delays or embargos in indexing CRs in PubMed, some of the recent CRs from 2020 were not indexed and therefore not included in the study. Although omission of non-PubMed indexed CRs was done purposefully, it is possible that additional insights could have been gained by including these CRs. While CRs are a large part of chiropractic research, trends in CRs may not be representative of all research types in the chiropractic field. The results of this review could have been affected by heterogeneity of study type, as we included both traditional retrospective CRs, which constituted the majority of included CRs, and prospective or $\mathrm{N}$-of- 1 case studies.

It is possible that confounding variables were missed that would have changed the qualitative and quantitative analyses. Dichotomizing cases as "rare" or "not rare" by a prevalence cutoff would have given insight into publication trends and associations for rare conditions.

Table 9 Examples of collaborative research case reports and larger subsequent studies

\section{First case report reference}

Plaugher G, (DC) Bachman TR (MD, rheumatology). Chiropractic management of a hypertensive patient. Journal of manipulative and physiological therapeutics. 1993 Oct 1;16 (8):544-9.

Dreyfuss $P$ (MD, physiatry), Michaelsen M (DC), Horne M. MUJA: manipulation under joint anesthesia/analgesia: a treatment approach for recalcitrant low back pain of synovial joint origin. Journal of manipulative and physiological therapeutics. 1995 Oct;18 (8):537-46.

\footnotetext{
Skaggs $C D(D C)$, Winchester BA, Vianin M, Prather H (DO, sports medicine). A manual therapy and exercise approach to meralgia paresthetica in pregnancy: a case report. Journal of Chiropractic Medicine. 2006 Sep 1;5 (3):92-6.

Aspegren $D(D C)$, Hyde T, Miller M. (MD, family medicine) Conservative treatment of a female collegiate volleyball player with costochondritis. Journal of manipulative and physiological therapeutics. 2007 May 1;30 (4): $321-5$.
}

Morningstar MW (DC), Strauchman MN (DO, family medicine). Management of a 59-year-old female patient with adult degenerative scoliosis using manipulation under anesthesia. Journal of chiropractic medicine. 2010 Jun 1;9 (2):77-83.

Seidman MB, Vining RD (DC), Salsbury SA (RN, PhD). Collaborative care for a patient with complex low back pain and long-term tobacco use: a case report. The Journal of the Canadian Chiropractic Association. 2015 Sep;59 (3):216.

\section{Larger study (only one example shown if multiple)}

Menke JM, Plaugher G, Carrari CA, Coleman RR, Vannetiello L, Bachman TR. Likelihood-Evidential Support and Bayesian Analysis on a Prospective Cohort of Children and Adolescents with Mild Scoliosis Under Chiropractic Management. Journal of the Arizona-Nevada Academy of Science. 2007 Jan 1:99-111.

Dreyfuss P, Michaelsen M, Pauza K, McLarty J, Bogduk N. The value of medical history and physical examination in diagnosing sacroiliac joint pain. Spine. 1996 Nov 15;21 (22):2594-602.

Skaggs CD, Prather H, Gross G, George JW, Thompson PA, Nelson DM. Back and pelvic pain in an underserved United States pregnant population: a preliminary descriptive survey. Journal of manipulative and physiological therapeutics. 2007 Feb 1;30 (2):130-4.

Aspegren D, Enebo BA, Miller M, White L, Akuthota V, Hyde TE, Cox JM. Functional scores and subjective responses of injured workers with back or neck pain treated with chiropractic care in an integrative program: a retrospective analysis of 100 cases. Journal of Manipulative and Physiological therapeutics. 2009 Nov 1;32 (9):765-71.

Morningstar MW, Strauchman MN, Weeks DA. Spinal manipulation and anterior headweighting for the correction of forward head posture and cervical hypolordosis: a pilot study. Journal of chiropractic medicine. 2003 Mar 1:2 (2):51-4.

Gudavalli MR, Salsbury SA, Vining RD, Long CR, Corber L, Patwardhan $A G$, Goertz CM. Development of an attention-touch control for manual cervical distraction: a pilot randomized clinical trial for patients with neck pain. Trials. 2015 Dec 1;16 (1):259. 
Diagnosis of a rare condition is a justification for publishing a $\mathrm{CR}$ and emphasizes the diagnostic process rather than treatment.

This review could have been strengthened by categorizing chiropractic authors by presence of a diplomate or master's degree in a clinical specialty such as radiology, pediatrics, nutrition, orthopedics/neuromusculoskeletal medicine, or sports. Specialization could be associated with greater publication volume, citation rate, and/or growth of certain CR topics. While only $37 \%$ of chiropractors have (or are working towards) a post-graduate diplomate or master's degree [2], such programs emphasize [129] or require [130] the publication of research, or offer it as an option to attain program credits [131]. In contrast, other research has shown that chiropractors generally lack the training required to conduct clinical research [14].

Data extraction was done independently (RT) and verified by a second author (JD) rather than in duplicate, which could have led to an increased error rate.

\section{Conclusions}

Chiropractic CRs have historically often described spinerelated musculoskeletal disorders in journals with a chiropractic focus. Although these are still the predominant themes, this review identified markers of increasing variety of chiropractic CRs, with trends towards a non-spine-related focus and non-chiropractic journals. Vascular-related case management CRs have emerged while those describing adverse effects have declined. Many disease categories and patient populations represent areas of need for chiropractic CRs such as pregnancy and pediatrics. Authors need to be aware of simple editorial features associated with a greater citation impact such as a title structure that follows recommended guidelines. We encourage chiropractors and chiropractic students to publish CRs to fill research gaps. In so doing, we contend that clinical advances will be better understood and well-known, and that the CRs would serve as the foundation for future research studies including randomized controlled trials. Taken together, this effort will increase the relevance of chiropractic medicine to clinicians and improve the health of patients.

\section{Abbreviations}

CARE: CAse REports; CR: Case report; ICD: International Classification of Disease; ICL: Index to Chiropractic Literature; IF: Impact factor; OR: Odds ratio; SJR: SCImago Journal Rank indicator

\section{Supplementary Information}

The online version contains supplementary material available at https://doi. org/10.1186/s12998-021-00374-5.

Additional file 1.

\section{Acknowledgements}

Not applicable.

\section{Authors' contributions}

RT conceived the idea, performed the literature search, and was responsible for data collection; RT and JD designed, organized, and implemented the study, contributed to data analysis and interpretation, wrote the manuscript, and provided critical manuscript review. Both authors read and approved the final manuscript.

\section{Funding}

This work was funded internally.

\section{Availability of data and materials}

The datasets supporting the conclusions of this article are available in the Figshare repository, https://doi.org/10.6084/m9.figshare.13591151.

\section{Declarations}

Ethics approval and consent to participate

This study was deemed "Not Human Subjects Research" by the University Hospitals Institutional Review Board.

\section{Consent for publication}

Not applicable.

\section{Competing interests}

The authors declare that they have no competing interests.

Received: 20 January 2021 Accepted: 13 April 2021

Published online: 28 April 2021

\section{References}

1. Murad MH, Sultan S, Haffar S, Bazerbachi F. Methodological quality and synthesis of case series and case reports. BMJ Evid Based Med. 2018;23:60-3 Royal Society of Medicine.

2. Esene IN, Kotb $A, E$ ElHusseiny $H$. Five is the maximum sample size for case reports: statistical justification, epidemiologic rationale, and clinical importance. World Neurosurg. 2014;82(5):e659-65. https://doi.org/10.1016/j. wneu.2014.05.014.

3. Alpi KM, Evans JJ. Distinguishing case study as a research method from case reports as a publication type. J Med Libr Assoc. 2019;107(1):1-5. https://doi. org/10.5195/jmla.2019.615.

4. Keating JC Jr, Caldwell S, Nguyen H, Saljooghi S, Smith B. A descriptive analysis of the Journal of manipulative and physiological therapeutics, 19891996. J Manip Physiol Ther. 1998;21 (8):539-52.

5. Keating J Jr, Larson K, Stephens M, Mick T. Journal of Manipulative \& Physiological Therapeutics: a bibliographic analysis. J Manip Physiol Ther. 1989;12:15-20.

6. Pohlman KA, Potocki EN, Lawrence DJ. A descriptive analysis and checklist critique of the articles in the Journal of clinical chiropractic pediatrics, 1996 to 2007. J Manip Physiol Ther. 2009;32(8):654-9. https://doi.org/10.1016/j. jmpt.2009.08.022.

7. Johnson CD, Green BN. Trends in articles published over the past 20 years in the journal of chiropractic education: country of origin, academic affiliation, and data versus nondata studies. J Chiropr Educ. 2008;22:4-11 Association of Chiropractic Colleges.

8. Lawrence D. Fourteen years of case-reports. J Manip Physiol Ther. 1991;14: 447-9.

9. Rupert RL. Case Reports. A Review of All Chiropractic Peer-Reviewed Research Journals. J Chiropr Case Rep. 1993;1.

10. Green BN, Johnson CD. How to write a case report for publication. J Chiropr Med. 2006;5(2):72-82. https://doi.org/10.1016/S0899-3467(07)60137-2 Elsevier.

11. Tuchin PJ, Bonello R. The design and presentation of a case study. Australas Chiropr Osteopathy. 1999;8:5 BioMed Central.

12. Weber KA, He X. Chiropractic students and research: assessing the research culture at a North American chiropractic college. J Chiropr Educ. 2010;24: 35-45 Association of Chiropractic Colleges.

13. Bronston $L$, Austin-McClellan LE, Lisi AJ, Donovan KC, Engle WW. A survey of American chiropractic association members' experiences, attitudes, and 
perceptions of practice in integrated health care settings. J Chiropr Med. 2015;14(4):227-39. https://doi.org/10.1016/j.jcm.2015.06.004 Elsevier.

14. Adams J, Lauche R, Peng W, Steel A, Moore C, Amorin-Woods LG, et al. A workforce survey of Australian chiropractic: the profile and practice features of a nationally representative sample of 2,005 chiropractors. BMC Complement Altern Med. 2017;17:14 Springer.

15. Schwarz I, Hondras MA. A survey of chiropractors practicing in Germany: practice characteristics, professional reading habits, and attitudes and perceptions toward research. Chiropr Osteopat. 2007;15:6 Springer.

16. Stuber K, Bussières A, Gotlib A. Chiropractic research capacity in Canada in 2008. J Can Chiropr Assoc. 2009;53:78.

17. Lawrence DJ. Case reports for the journal of chiropractic medicine. J Chiropr Med. 2002;1:47 Elsevier.

18. Cheryl Hawk D. Evidence-based case reports. J Clin Chiropr Pediatr. 2018;17(1): 1388.

19. Merritt L. Commentary: Case reports: an important contribution to chiropractic literature. J Can Chiropr Assoc. 2007:51:72.

20. Bolton J. Evidence-based case reports. J Can Chiropr Assoc. 2014;58:6.

21. Budgell B. Guidelines to the writing of case studies. J Can Chiropr Assoc 2008;52:199.

22. Waalen JK. Single subject research designs. J Can Chiropr Assoc. 1991;35:95.

23. Emary PC, Taylor JA. Imaging case reviews. J Can Chiropr Assoc. 2016;60:258

24. Young M. A case in point. Clin Chiropr. 2007;10(3):117-8. https://doi.org/10.1 016/j.clch.2007.07.001.

25. Vallone S. The value of case reports. J Clin Chiropr Pediatr. 2014;14(3):1166.

26. Jones-Harris AR. The evidence-based case report: a resource pack for chiropractors. Clin Chiropr. 2003;6(2):73-84. https://doi.org/10.1016/S1479-23 54(03)00022-1 Churchill Livingstone.

27. Ebrall P, Murakami Y. Constructing a credible case report: assembling your evidence. J Contemp Chiropr. 2018;1:45-58.

28. Gleberzon BJ, Killinger LZ. The journal article cookbook. J Manip Physiol Ther. 2004;27(7):481-92. https://doi.org/10.1016/j.jmpt.2004.06.010.

29. Green BN, Johnson CD. Writing patient case reports for peer-reviewed journals: secrets of the trade. J Sport Chiropr Reh. 2000;14:51-9 Lippincott, Williams and Wilkins

30. Vernon $\mathrm{H}$. The single-case study experimental design in general chiropractic practice. J Can Chiropr Assoc. 1981;25:15.

31. Aker PD, McDermaid C, Opitz BG, White MW. Searching chiropractic literature: a comparison of three computerized databases. J Manip Physiol Ther. 1996;19:518-24.

32. Wenban $A B$. Inappropriate use of the title'chiropractor'and term'chiropractic manipulation'in the peer-reviewed biomedical literature. Chiropr Osteopat. 2006;14:16 Springer.

33. Terrett A. Misuse of the literature by medical authors in discussing spinal manipulative therapy injury. J Manip Physiol Ther. 1995;18(4):203-10.

34. Gagnier JJ, Kienle G, Altman DG, Moher D, Sox H, Riley D, et al. The CARE guidelines: consensus-based clinical case reporting guideline development J Med Case Rep. 2013;7:223 Springer.

35. ICD-10 Version: 2010. Available from: https://icd.who.int/browse10/2010/en. Cited 2021 Jan 16

36. Caufield JH, Zhou Y, Garlid AO, Setty SP, Liem DA, Cao Q, et al. A reference set of curated biomedical data and metadata from clinical case reports. Sci Data. 2018;5:1-18 Nature Publishing Group.

37. World Health Organization. International Statistical Classification of Diseases and Related Health Problems 10th Revision. Geneva: World Health Organization; 2010.

38. The Web's Free 2021 ICD-10-CM/PCS Medical Coding Reference. Available from: https://www.icd10data.com/. Cited 2021 Jan 16

39. Jesus TS, Gianola S, Castellini G, Colquhoun H, Brooks D. Evolving trends in physiotherapy research publications between 1995 and 2015. Physiother Can. 2020;72:122-31 University of Toronto Press.

40. Mogil JS, Simmonds K, Simmonds MJ. Pain research from 1975 to 2007: a categorical and bibliometric meta-trend analysis of every research paper published in the journal, Pain. Pain. 2009:142:48-58 Elsevier.

41. Pediatric Exclusivity Study Age Group. U.S. Food and Drug Administration; 2000.

42. Russell AF, Loder RT, Gudeman AS, Bolaji P, Virtanen P, Whipple EC, et al. A bibliometric study of authorship and collaboration trends over the past 30 years in four major musculoskeletal science journals. Calcif Tissue Int. 2019; 104(3):239-50. https://doi.org/10.1007/s00223-018-0492-3 Springer.

43. Martín-Martín A, Orduna-Malea E, Thelwall M, López-Cózar ED. Google scholar, web of science, and Scopus: a systematic comparison of citations in
252 subject categories. J Informetr. 2018;12(4):1160-77. https://doi.org/10.1 016/j.joi.2018.09.002 Elsevier.

44. Scimago Journal \& Country Rank. Available from: https://www.scimagojr. com/. Cited 2021 Jan 16

45. Rousseau R, Achom A, Berhe H, Dhamdhere S, Esguerra A, Hoan N, et al. On the relation between the WoS impact factor, the Eigenfactor, the SCImago journal rank, the article influence score and the journal h-index. 2009;

46. Harzing A-W, van der Wal R. Comparing the Google scholar h-index with the ISI journal impact factor. Res Int Manag Prod Serv Acad. 2008;1.

47. Jacques TS, Sebire NJ. The impact of article titles on citation hits: an analysis of general and specialist medical journals. JRSM Short Rep. 2010;1:1-5 SAGE Publications Sage UK: London, England.

48. Text Analyzer - Text analysis Tool - Counts Frequencies of Words, Characters, Sentences and Syllables. Available from: https://www.onlineutility.org/text/analyzer.jsp. Cited 2021 Jan 16

49. Thelwall M, Wilson P. Regression for citation data: an evaluation of different methods. J Informetr. 2014;8(4):963-71. https://doi.org/10.1016/j.joi.2014.09. 011 Elsevier.

50. Bornmann L. How to analyze percentile citation impact data meaningfully in bibliometrics: the statistical analysis of distributions, percentile rank classes, and top-cited papers. J Assoc Inf Sci Technol. 2013;64:587-95 Wiley Online Library.

51. Harris S, Wood K. Resolution of infantile Erb's palsy utilizing chiropractic treatment. J Manip Physiol Ther. 1993;16(6):415-8.

52. Holleman AC, Nee J, Knaap SF. Chiropractic management of breast-feeding difficulties: a case report. J Chiropr Med. 2011;10(3):199-203. https://doi. org/10.1016/j.jcm.2011.01.010 Elsevier.

53. Alcantara J, Anderson R. Chiropractic care of a pediatric patient with symptoms associated with gastroesophageal reflux disease, fuss-cryirritability with sleep disorder syndrome and irritable infant syndrome of musculoskeletal origin. J Can Chiropr Assoc. 2008;52:248.

54. McLean M. In good alignment. Midwifery Today Childbirth Educ. 1995;(33):11

55. Howell ER. Pregnancy-related symphysis pubis dysfunction management and postpartum rehabilitation: two case reports. J Can Chiropr Assoc. 2012; 56:102.

56. Kruse RA, Gudavalli S, Cambron J. Chiropractic treatment of a pregnant patient with lumbar radiculopathy. J Chiropr Med. 2007;6(4):153-8. https:// doi.org/10.1016/j.jcme.2007.08.005 Elsevier.

57. Skaggs CD, Winchester BA, Vianin M, Prather H. A manual therapy and exercise approach to meralgia paresthetica in pregnancy: a case report. J Chiropr Med. 2006;5(3):92-6. https://doi.org/10.1016/S0899-3467(07)60140-2 Elsevier.

58. Ko GD, Mindra S, Lawson GE, Whitmore S, Arseneau L. Case series of ultrasound-guided platelet-rich plasma injections for sacroiliac joint dysfunction. J Back Musculoskelet Rehabil. 2017;30(2):363-70. https://doi. org/10.3233/BMR-160734 IOS Press.

59. Oakley PA, Ehsani NN, Harrison DE. Non-surgical reduction of lumbar hyperlordosis, forward sagittal balance and sacral tilt to relieve low back pain by chiropractic BioPhysics ${ }^{\oplus}$ methods: a case report. J Phys Ther Sci. 2019;31(10):860-4. https://doi.org/10.1589/jpts.31.860 The Society of Physical Therapy Science.

60. Fortner MO, Oakley PA, Harrison DE. Cervical extension traction as part of a multimodal rehabilitation program relieves whiplash-associated disorders in a patient having failed previous chiropractic treatment: a CBP® ${ }^{\oplus}$ case report. $J$ Phys Ther Sci. 2018;30(2):266-70. https://doi.org/10.1589/jpts.30.266 The Society of Physical Therapy Science.

61. Haggard JS, Haggard JB, Oakley PA, Harrison DE. Reduction of progressive thoracolumbar adolescent idiopathic scoliosis by chiropractic biophysics ${ }^{\circledast}\left(\mathrm{CBP}^{\oplus}\right)$ mirror image ${ }^{\circledast}$ methods following failed traditional chiropractic treatment: a case report. J Phys Ther Sci. 2017;29(11):2062-7. https://doi.org/10.1589/jpts.29.2062 The Society of Physical Therapy Science

62. Cornelson SM, Johnnie ED, Kettner NW. Neural mobilization in a 54-year-old woman with postoperative spinal adhesive arachnoiditis. J Chiropr Med. 2018:17(4):283-8. https://doi.org/10.1016/j.jcm.2018.07.004 Elsevier.

63. Francio $V T$, Boesch $R$, Tunning $M$. Treatment of a patient with posterior cortical atrophy (PCA) with chiropractic manipulation and dynamic neuromuscular stabilization (DNS): a case report. J Can Chiropr Assoc. 2015; 59:37.

64. Vining RD, Gosselin DM, Thurmond J, Case K, Bruch FR. Interdisciplinary rehabilitation for a patient with incomplete cervical spinal cord injury and multimorbidity: a case report. Medicine. 2017;96:e7837. 
65. St-Onge E, MacIntyre IG, Galea AM. Multidisciplinary approach to nonsurgical management of inguinal disruption in a professional hockey player treated with platelet-rich plasma, manual therapy and exercise: a case report. J Can Chiropr Assoc. 2015:59:390.

66. Branchini M, Lopopolo F, Andreoli E, Loreti I, Marchand AM, Stecco A. Fascial Manipulation ${ }^{\circledast}$ for chronic aspecific low back pain: a single blinded randomized controlled trial. F1000Res. 2016;4 Available from: http://www. ncbi.nlm.nih.gov/pmc/articles/PMC4706049/. Cited 2017 Jan 8.

67. Battaglia PJ, Craig K, Kettner NW. Ultrasonography in the assessment of lateral ankle ligament injury, instability, and anterior ankle impingement: a diagnostic case report. J Chiropr Med. 2015;14(4):265-9. https://doi.org/10.1 016/j.jcm.2015.05.004 Elsevier.

68. Cates JR. Abdominal aortic aneurysms: clinical diagnosis and management. J Manip Physiol Ther. 1997;20:557-61.

69. Mattox R, Smith LW, Kettner NW. Recognition of spontaneous vertebral artery dissection preempting spinal manipulative therapy: a patient presenting with neck pain and headache for chiropractic care. J Chiropr Med. 2014;13(2):90-5. https://doi.org/10.1016/j.jcm.2014.06.011 Elsevier.

70. Tarola G, Phillips RB. Chiropractic response to a spontaneous vertebral artery dissection. J Chiropr Med. 2015;14(3):183-90. https://doi.org/10.1016/j.jcm.2 015.10.003 Elsevier.

71. Futch D, Schneider MJ, Murphy D, Grayev A. Vertebral artery dissection in evolution found during chiropractic examination. BMJ Case Rep. 2015;2015: bcr2015212568 BMJ Publishing Group.

72. Liebich JM, Reinke TS. Presentation of an 85-year-old woman with musculoskeletal pain to a chiropractic clinic: a Case of ischemic stroke. Chiropr Med. 2014;13(1):49-54. https://doi.org/10.1016/j.jcm.2014.01.005 Elsevier.

73. Kier AL, McCarthy PW. Cerebrovascular accident without chiropractic manipulation: a case report. J Manip Physiol Ther. 2006;29(4):330-5. https:// doi.org/10.1016/j.jmpt.2006.03.001 Elsevier

74. Stainsby BE, Muir BJ, Miners AL. Upper extremity deep vein thrombosis presenting to a chiropractic clinic: a description of 2 cases. J Chiropr Med. 2012;11(4):286-92. https://doi.org/10.1016/j.jcm.2012.02.004.

75. Mattox R, Trager RJ, Kettner NW. Effort thrombosis in 2 athletes suspected of musculoskeletal injury. J Chiropr Med. 2019;18(3):213-8. https://doi.org/1 0.1016/j.jcm.2019.01.004

76. Fernandez M, Pollard H, McHardy A. A patient with deep vein thrombosis presenting to a chiropractic clinic: a case report. J Manip Physiol Ther. 2007; 30(2):144-51. https://doi.org/10.1016/j.jmpt.2006.12.009 Elsevier.

77. Kopansky-Giles DR, Grod JP, Crowther ER. Acute proximal deep vein thrombosis: presentation in a chiropractic office. J Can Chiropr Assoc. 1995; 39:205.

78. de Boer NJ, Knaap SF, de Zoete A. Clinical detection of abdominal aortic aneurysm in a 74-year-old man in chiropractic practice. J Chiropr Med. 2010; 9(1):38-41. https://doi.org/10.1016/j.jcm.2009.12.002.

79. Patel SN, Kettner NW. Abdominal aortic aneurysm presenting as back pain to a chiropractic clinic: a case report. J Manip Physiol Ther. 2006;29:409-e1 Elsevier.

80. Weston J. Chiropractic management of abdominal aortic aneurysm: a case report. J Can Chiropr Assoc. 1995;39:75.

81. Vernon L, Peacock J, Esposito A. Abdominal aortic aneurysms presenting as low back pain: a report of two cases. J Manip Physiol Ther. 1986;9(1):47-50.

82. Larkin-Thier SM, Livdans-Forret AB, Harvey PJ. Headache caused by an intracranial aneurysm in a 32-year-old woman. J Manip Physiol Ther. 2007; 30(2):140-3. https://doi.org/10.1016/j.jmpt.2006.12.010 Elsevier.

83. Kaufman RL. Popliteal aneurysm as a cause of leg pain in a geriatric patient. J Manip Physiol Ther. 2004;27:427 Elsevier.

84. Erfanian P. Patient with signs and symptoms of myocardial infarction, presenting to a chiropractic office: a case report. J Can Chiropr Assoc. 2001;45:35.

85. Quon J, Thiel H, Cassidy J, Donat J. Anticoagulant therapy and subdural hematoma formation. J Manip Physiol Ther. 1990;13(1):30-2.

86. Haldeman S, Rubinstein S. Compression fractures in patients undergoing spinal manipulative therapy. J Manip Physiol Ther. 1992;15:450-4.

87. Whedon JM, Quebada PB, Roberts DW, Radwan TA. Spinal epidural hematoma after spinal manipulative therapy in a patient undergoing anticoagulant therapy: a case report. J Manip Physiol Ther. 2006;29(7):582-5. https://doi.org/10.1016/j.jmpt.2006.06.017 Elsevier.

88. Donzis PB, Factor JS. Visual field loss resulting from cervical chiropractic manipulation. Am J Ophthalmol. 1997;123(6):851-2. https://doi.org/10.1016/ S0002-9394(14)71144-4 Elsevier.
89. Nykoliation J, Cassidy J, Dupuis P. Osteitis condensans illii-a sacrolliac stress phenomenon: a report of a case. J Can Chiropr Assoc. 1984;28:209.

90. Christensen M, Hyland J, Goertz C, Kollasch M. Practice analysis of chiropractic 2015. Greeley: National Board of Chiropractic Examiners; 2015.

91. Bolton P, Stick P, Lord R. Failure of clinical tests to predict cerebral ischemia before neck manipulation. J Manip Physiol Ther. 1989;12(4):304-7.

92. Kattah JC, Talkad AV, Wang DZ, Yu-Hsiang H, Newman-Toker David E. HINTS to diagnose stroke in the acute vestibular syndrome. Stroke. 2009;40:350410 American Heart Association.

93. Church EW, Sieg EP, Zalatimo O, Hussain NS, Glantz M, Harbaugh RE. Systematic review and meta-analysis of chiropractic care and cervical artery dissection: no evidence for causation. Cureus. 2016:8:e498.

94. Cassidy JD, Boyle E, Côté P, He Y, Hogg-Johnson S, Silver FL, et al. Risk of vertebrobasilar stroke and chiropractic care: results of a population-based case-control and case-crossover study. J Manip Physiol Ther. 2009;32(2): S201-8. https://doi.org/10.1016/j.jmpt.2008.11.020 Elsevier.

95. Donovan J, Cassidy JD, Cancelliere C, Poulsen E, Stochkendahl MJ, Kilsgaard J, et al. Beyond the spine: a new clinical research priority. J Can Chiropr Assoc. 2015:59:6.

96. Research Summary and Strategic Research Opportunities. Chiropractors' Association of Australia Tertiary Education and Research Committee v1.1. Parramatta: Chiropractors' Association of Australia; 2016.

97. Hammer WI. The effect of mechanical load on degenerated soft tissue. J Bodyw Mov Ther. 2008;12(3):246-56. https://doi.org/10.1016/j.jbmt.2008.03. 007 Elsevier.

98. Miners AL, Bougie TL. Chronic Achilles tendinopathy: a case study of treatment incorporating active and passive tissue warm-up, Graston technique ${ }^{\circledast}, \mathrm{ART}^{\circledast}$, eccentric exercise, and cryotherapy. J Can Chiropr Assoc. 2011;55:269

99. Howitt S, Jung S, Hammonds N. Conservative treatment of a tibialis posterior strain in a novice triathlete: a case report. J Can Chiropr Assoc. 2009:53:23.

100. Papa JA. Conservative management of De Quervain's stenosing tenosynovitis: a case report. J Can Chiropr Assoc. 2012;56:112 The Canadian Chiropractic Association.

101. Yuill EA, Pajaczkowski JA, Howitt SD. Conservative care of sports hernias within soccer players: a case series. J Bodyw Mov Ther. 2012;16(4):540-8. https://doi.org/10.1016/j.jbmt.2012.04.004 Elsevier.

102. Papa JA. Conservative management of Achilles Tendinopathy: a case report. J Can Chiropr Assoc. 2012;56:216.

103. Aspegren D, Hyde T, Miller M. Conservative treatment of a female collegiate volleyball player with costochondritis. J Manip Physiol Ther. 2007;30(4):3215. https://doi.org/10.1016/j.jmpt.2007.03.003 Elsevier.

104. Drake ED, Seckington AS, Sullivan SG, Behrens S. The sensory-motor auditory visual education (SAVE) program for adults with prior concussions: a prospective case series. Integr Med Res. 2020;9:100397.

105. Marshall CM, Vernon H, Leddy JJ, Baldwin BA. The role of the cervical spine in post-concussion syndrome. Phys Sportsmed. 2015:43(3):274-84. https:// doi.org/10.1080/00913847.2015.1064301.

106. Olson HM, Tunning MJ, Boesch RJ. Chiropractic Management of Musculoskeletal Symptoms in a 14-year-old hockey player with Postconcussion symptoms: a case report. J Chiropr Med. 2016;15(3):208-13. https://doi.org/10.1016/j.jcm.2016.04.006 Elsevier.

107. Wasylynko DE. Chiropractic care of a 10-year-old boy with nonorganic gait disorder: a case report. J Chiropr Med. 2017;16(2):175-9. https://doi.org/10.1 016/j.jcm.2017.02.003 Elsevier.

108. Swingen LA, Goldsmith R, Boothby J, McDermott T, Kleibel C. Video Nystagmography to Monitor Treatment in Mild Traumatic Brain Injury: A Case Report. Integr Med (Encinitas). 2017:16:46 InnoVision Media.

109. Morgan WE, Morgan CP. Chiropractic care of a patient with neurogenic heterotopic ossification of the anterior longitudinal ligament after traumatic brain injury: a case report. J Chiropr Med. 2014;13(4):260-5. https://doi.org/1 0.1016/j.jcm.2014.08.001 Elsevier.

110. Gergen DM. Management of mild traumatic brain injury symptoms in a 31year-old woman using cervical manipulation and acupuncture: a case report. J Chiropr Med. 2015;14(3):220-4. https://doi.org/10.1016/j.jcm.2015. 08.006 Elsevier.

111. Peterson C. A case study of chiropractic management of pregnancy-related heartburn with postulated fetal epigenome implications. Explore. 2012;8(5): 304-8. https://doi.org/10.1016/j.explore.2012.06.001 Elsevier. 
112. Iyer MM, Skokos E, Piombo D. Chiropractic management using multimodal therapies on 2 pediatric patients with constipation. J Chiropr Med. 2017; 16(4):340-5. https://doi.org/10.1016/j.jcm.2017.06.004 Elsevier.

113. Quist DM, Duray SM. Resolution of symptoms of chronic constipation in an 8-year-old male after chiropractic treatment. J Manip Physiol Ther. 2007; 30(1):65-8. https://doi.org/10.1016/j.jmpt.2006.11.005 Elsevier.

114. Faye LJ, Budgell BS. Presumptive spondylogenic pruritus: a case study. J Can Chiropr Assoc. 2020;64:139.

115. Kaminskyj A, Frazier M, Johnstone K, Gleberzon BJ. Chiropractic care for patients with asthma: a systematic review of the literature. J Can Chiropr Assoc. 2010;54(1):24-32.

116. Haas M, Bronfort G, Evans RL. Chiropractic clinical research: progress and recommendations. J Manip Physiol Ther. 2006;29(9):695-706. https://doi. org/10.1016/j.jmpt.2006.09.005 Elsevier.

117. French SD, Beliveau PJ, Bruno P, Passmore SR, Hayden JA, Srbely J, et al. Research priorities of the Canadian chiropractic profession: a consensus study using a modified Delphi technique. Chiropr Man Therap. 2017;25:38 Springer.

118. Rubinstein SM, Bolton J, Webb AL, Hartvigsen J. The first research agenda for the chiropractic profession in Europe. Chiropr Man Therap. 2014;22:9 Springer.

119. Vernon H. The development of a research agenda for the Canadian chiropractic profession: report of the consortium of Canadian chiropractic research Centres, November 2000. J Can Chiropr Assoc. 2002;46:86.

120. Mestan MA. Posterior fossa ischemia and bilateral vertebral artery hypoplasia. J Manip Physiol Ther. 1999;22(4):245-9. https://doi.org/10.1016/ S0161-4754(99)70051-5 Elsevier.

121. Lowden T, Keating J Jr, Meeker W. A multivariate time-series descriptive case study of chiropractic care in the treatment of cervical pain. J Manip Physiol Ther. 1986;9(4):267-77.

122. Singh BB, Zarow FM, Traina A, Scaringe J. A specific electrotherapy technique in the treatment of osteoarthritis of the knee: three case reports. Altern Ther Health Med. 2000;6:112 InnoVision Health Media, Inc.

123. Reggars JW, French SD. Sometimes they may be zebras: herpes zoster of the L2 spinal nerve. A case report. Australas Chiropr Osteopathy. 1996;5(2): 45-6.

124. Murphy D, Goldstein D, Katz M. Chiropractic adjustment to the cervical spine and the Arnold-Chiari malformation. J Manip Physiol Ther. 1993;16(8): 550-5.

125. Berger GN. Practical benefits of case reporting. In: Packer CD, Berger GN, Mookherjee $S$, editors. Writing case reports: a practical guide from conception through publication. Cham: Springer International Publishing; 2017. p. 33-42. Available from: https://doi.org/10.1007/978-3-319-41899-5_4. Cited 2020 Sep 26

126. Hawk C, Khorsan R, Lisi AJ, Ferrance RJ, Evans MW. Chiropractic care for nonmusculoskeletal conditions: a systematic review with implications for whole systems research. J Altern Complement Med. 2007;13:491-512 Mary Ann Liebert, Inc. 2 Madison Avenue Larchmont, NY 10538 USA.

127. McHardy A, Hoskins W, Pollard H, Onley R, Windsham R. Chiropractic treatment of upper extremity conditions: a systematic review. J Manip Physiol Ther. 2008;31(2):146-59. https://doi.org/10.1016/j.jmpt.2007.12.004 Elsevier.

128. Alcantara J, Alcantara JD, Alcantara J. The chiropractic Care of Infants with colic: a systematic review of the literature. Explore. 2011;7(3):168-74. https:// doi.org/10.1016/j.explore.2011.02.002.

129. Mestan MA, Taylor JAM, Blackshaw GL, McDonald JC. Commentary: establishing an accredited master of science in diagnostic imaging degree at a chiropractic college. J Manip Physiol Ther. 2006;29(5):410-3. https://doi. org/10.1016/j.jmpt.2006.04.008 Elsevier.

130. Diplomate in Clinical Chiropractic Pediatrics (DICCP) ICA Council on Chiropractic Pediatrics. Available from: https:/www.icapediatrics.com/ diplomate-program/. Cited 2021 Mar 5

131. ACA Council on Occupational Health. Available from: http://www.acacoh. com/DACBOH_ACBOH.htm. Cited 2021 Mar 5

\section{Publisher's Note}

Springer Nature remains neutral with regard to jurisdictional claims in published maps and institutional affiliations.

\section{Ready to submit your research? Choose BMC and benefit from:}

- fast, convenient online submission

- thorough peer review by experienced researchers in your field

- rapid publication on acceptance

- support for research data, including large and complex data types

- gold Open Access which fosters wider collaboration and increased citations

- maximum visibility for your research: over $100 \mathrm{M}$ website views per year

At BMC, research is always in progress.

Learn more biomedcentral.com/submissions 